Effects of racism and discrimination on mental health problems among young people in Victoria, Australia during COVID-19 lockdown

Kate Doery (kate.doery@anu.edu.au), ${ }^{\mathrm{a}, \mathrm{b}}$ Roxanne Jones (roxanne.jones@anu.edu.au), ${ }^{\mathrm{c}}$

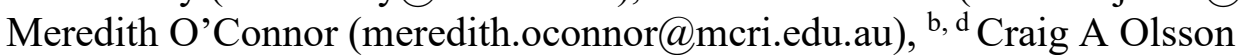

(Craig.Olsson@rch.org.au), ${ }^{\text {d, e, f }}$ Shuaijun Guo (jun.guo@mcri.edu.au), ${ }^{\text {a, b, d }}$ Linette Harriott (lharriott@cmy.net.au), ${ }^{g}$ Carmel Guerra (carmel@cmy.net.au) ${ }^{\mathrm{g}}$ and Naomi Priest (naomi.priest@anu.edu.au)*a,b

* Corresponding Author- Professor Naomi Priest, RSSS Building, Australian National University, 146 Ellery Crescent, Canberra, Australian Capital Territory, Australia. Naomi.priest@anu.edu.au

a Australian National University, Centre for Social Research and Methods, 146 Ellery Cres, Canberra, Australian Capital Territory, Australia

b Murdoch Children's Research Institute, Centre for Community Child Health, Royal Children's Hospital, 50 Flemington Rd, Parkville, Victoria, Australia

${ }^{c}$ Australian National University, National Centre for Epidemiology and Population Health, Research School of Population Health, 62 Mills Road, Canberra, Australian Capital Territory, Australia

d University of Melbourne, Department of Paediatrics, Royal Children's Hospital 50 Flemington Road, Parkville, Victoria, Australia

e Deakin University, Centre for Social and Early Emotional Development, School of Psychology, 221 Burwood Hwy, Burwood, Victoria, Australia

${ }^{f}$ Murdoch Children's Research Institute, Centre for Adolescent Health, Royal Children's Hospital, 50 Flemington Rd, Parkville, Victoria, Australia

${ }^{\mathrm{g}}$ Centre for Multicultural Youth, 304 Drummond St. Carlton, Victoria, Australia. 


\section{Author contribution}

KD: conceptualisation, formal analysis, data curation, writing-original draft preparation, RJ, MO, CA \& SG: writing- review and editing, methodology support, LH \& CG: conceptualisation, investigation, NP: conceptualisation, writing- review and editing.

\section{Acknowledgement}

The authors would like to acknowledge the Centre for Multicultural Youth, in particular Edmee Kenny, for their support with data collection and recruitment of participants for this project. This research did not receive any specific grant from funding agencies in the public, commercial or not-for-profit sectors.

\section{Funding}

NP supported by the National Health and Medical Research Council (NHMRC) Career Development Fellowship (APP1123677) and an Australian National University Translational Fellowship; RR is supported by an NHMRC Postgraduate Scholarship (1189913).

\section{Declaration of competing interest}

The authors declare that they have no known competing interest related to this paper. 


\title{
Effects of racism and discrimination on mental health problems among young people in Victoria, Australia during COVID-19 lockdown
}

\begin{abstract}
Racism and discrimination are fundamental determinants of health inequities, with children and young people particularly vulnerable. Reports of racism and discrimination rose sharply in 2020 along with the global coronavirus (COVID-19) pandemic. We examined racism, discrimination (e.g. direct, vicarious, heightened vigilance, and worries about experiencing racial discrimination), COVID-19 pandemic related stressors (e.g. access to support services, changes to personal relationships, and financial hardship) and their associations with mental health problems (e.g. worry, lack of concentration, and irritability) using a series of linear regression models in young people during the Australian national COVID-19 lockdowns in 2020. Data was collected using the Racism During COVID-19 survey, a community-based, cross-sectional online survey. 363 young people aged 16-24 living in Victoria, Australia were included in our analysis, $45.4 \%$ self-identified as being from a multicultural background and $3.7 \%$ as Aboriginal and/or Torres Strait Islander. $73.7 \%$ reported direct discrimination, $88.9 \%$ reported vicarious discrimination, $84.3 \%$ reported heightened vigilance and, $62.8 \%$ reported worries about experiencing racial discrimination. Half $(51.3 \%)$ the participants experienced one or two COVID-19 related stressors and one third (34.2\%) experienced three or more. Almost all (91.9\%) reported high levels for two or more negative mental health problems. Experiences of direct discrimination, vicarious racism, heightened vigilance, worries about experiencing racial discrimination, and multiple COVID-19 related stressors $(3+)$ were each associated with negative mental health problems, after adjusting for ethnicity, age and gender and socio-economic position. Addressing racism and discrimination is critical to addressing social determinants of health for young people.
\end{abstract}

\section{Key Words}

Racism; Discrimination; Young People; Mental Health; COVID-19; Australia 


\section{Background}

Racism and discrimination are fundamental determinants of health and health inequities.[1] Children and young people are considered particularly vulnerable to racism's harmful health effects.[2] Reports of racism and discrimination rose sharply in 2020 along with the global COVID-19 pandemic, which disproportionally affected racialised groups across the world.[35] Racism as a public health emergency, the 'other pandemic', and a major threat to public health has been recently recognised by leading medical journals and agencies internationally as well as by community leaders and peak bodies in many countries, including in Australia.[3, 6-9] Globally, the Black Lives Matter (BLM) movement has also drawn much needed attention to systemic racial injustices and systemic and institutional racism and discrimination. In Australia, the BLM movement has primarily focused on racism and injustice experienced by Aboriginal and Torres Strait Islander peoples [7, 10, 11] and to a lesser extent on racialised groups such as migrants.

Racism is an organised system of oppression that categorises and ranks groups of people, with no biological basis, into 'races' and inequitably distributes resources and power to those considered inferior.[12-14] Racial discrimination is the behavioural manifestation of racism and can be expressed as stereotyping, prejudice or unfair treatment.[14] Racism and racial discrimination operate across multiple levels. Structural and systemic racism operates at a societal level whereby discriminatory beliefs and values are embedded into systems, institutions, laws, policies and practices.[15-17] Interpersonal racial discrimination occurs between individuals and is the intentional or unintentional behavioural expression of racism, including racially motivated assaults, abuse, suppression, and exclusion.[14, 17] Internalised racism occurs when individuals accept dominant views and stereotypes about themselves and other members of their racial/ethnic/cultural group.[17] Each of these levels of racism impacts health and health inequities throughout the life course, often in multiple and mutually reinforcing ways.

Empirical work on racism and health has primarily focused on interpersonal discrimination among adults. There is a growing body of work that documents links between direct experiences of racial discrimination and adverse health outcomes for children and young people, including asthma, inflammation and cardiometabolic risk markers, depression, anxiety, suicidality and associated mental health risk factors such as sleep difficulties.[2, 18] Similarly, there is growing evidence to suggest that vicarious racism or second-hand experiences of racial 
discrimination (where people witness or hear about others' experiences) are associated with negative physical and mental health outcomes for children and young people.[19, 20] However, this remains under-researched, particularly outside of the United States. In particular, few studies globally consider the health impacts of vicarious exposure to racism for children and young people.[2, 21]

In addition to direct and vicarious experiences of racism, racism related vigilance - anticipatory racism related stress and worry regarding discrimination - is also increasingly recognised as a powerful way in which racism is related to adverse health outcomes throughout the lifecourse. Vigilance is a psychological coping mechanism whereby individuals are more aware of surroundings and take certain actions to mitigate potential negative outcomes,[22] with racerelated vigilance being 'preparation for and anticipation of discrimination.'[23 p.101] A chronic state of heightened vigilance can have detrimental effects on health and health disparities, including increased risk for mental health problems such as depression and stressrelated problems.[23, 24] Empirical evidence documents associations between race related vigilance and increased stress, cardiovascular stress responses, poor psychological health, and poor sleep among adults.[23-28] There is also some suggestion that race related vigilance may increase the risk for cardiovascular problems with evidence of increased arterial elasticity in African-American boys.[29] Further empirical research is required to better understand experiences of heightened race related vigilance and associated health impacts, particularly in younger racialised populations.

A further outstanding research priority is to understand how discrimination experiences and responses combine with other stressor exposures to influence young people's health.[30] The full contribution of stressors related to racism and the burden of stressor exposure associated with belonging to a racialised group is only partially captured by self-reported discrimination measures and racism related stress experiences.[30] This includes attention to stressors beyond interpersonal discrimination that are linked to the wider social, physical and built environment. These may not at face value appear linked to racism, yet can be considered reflections of the broader structural and systemic influence of racism on health.[30, 31] In the context of the COVID-19 pandemic, this means the necessity of capturing both experiences of discrimination and racism related stressors, as well as the burden of other pandemic related stressors, among young people. While children and young people in Australia have had low levels of COVID19 related morbidity and mortality to date,[32] measures to contain the spread of COVID-19, 
including social distancing, mask wearing and stay at home orders (lockdown), have profoundly impacted young people's social environments, access to education and employment, family financial situations and living conditions.[33] Documenting experiences of discrimination and racism related stress, as well as wider stressor burden and associated health impacts among young people, is required to inform policy and practice focused on pandemic recovery and population health.

\subsection{Study context}

This study is located in Victoria, Australia, a country of 25.7 million, of whom $26 \%$ live in Victoria.[34] Australia is a multicultural nation, a quarter of all Australians are born overseas, [34] migrating from Europe and Asia, with migration from the Middle East and Africa on the rise.[35] Australia's First Nations people - Aboriginal and Torres Strait Islander Australians - comprise 3.3\% of the population, [35] however experience some of the greatest health inequities globally.[36]

Australia was one of the earliest adopters of physical distancing and isolation measures in response to the emerging COVID-19 threat, and went on to impose some of the strictest COVID-19 restrictions in the world.[37] These measures have seen relatively low numbers of community transmitted cases and coronavirus related deaths in Australia. By October 2021, eighteen months on from the start of the pandemic, Australia had conducted just over 41.5 million tests and recorded almost 149,400 cases ( $0.4 \%$ test positive) and 1,577 deaths.[32] Melbourne, Victoria's capital city, endured two periods (March-April and June-October) of COVID-19 restrictions in 2020, with Melbournians generally confined in their houses with limited opportunity for social interactions in one of the world's longest and strictest lockdowns of nearly four months between March and October 2020. On October 212021 Melbourne left lockdown after becoming the world's most locked-down city, enduring 262 days in lockdown since March 2020.

In this study, we examined experiences of young people in Victoria, Australia, throughout the COVID-19 lockdown in June 2020. The Centre for Multicultural Youth (CMY) undertook the Racism during COVID-19 Survey, an online, community-based, cross-sectional survey targeting multicultural young people aged 16-24 years living in Victoria. Young people were asked about their experiences of direct discrimination, vicarious racial discrimination, heightened vigilance, worries about experiencing racial discrimination, COVID-19 related 
stressors and their health and wellbeing, including mental health. The composition of the sample and the stringency of the Victorian Government response to the COVID-19 threat provide a unique opportunity to understand how the COVID-19 lockdown may disproportionally impact multicultural young people. Specifically, the aims of this study are threefold: (1) to estimate the prevalence of direct discrimination, vicarious racism, heightened vigilance, worries about experiencing racial discrimination, COVID-19 related stressors and mental health problems in young multicultural Victorians during lockdown; (2) to examine associations between self-reported ethnicity and experiences of discrimination and COVID-19 related stressors; and (3) to examine associations between discrimination, COVID-19 related stressors and mental health problems.

\section{Methods}

\subsection{Data Source}

In June 2020, the CMY, a not-for-profit organisation based in Melbourne, Australia, that provides specialist knowledge and support to young people from migrant and refugee backgrounds, conducted a rapid response in-house service improvement survey, CMY Racism During COVID-19. This survey was intended to facilitate a better understanding of the nature and impact of racial discrimination during COVID-19 restrictions among young people and the impacts on their health and wellbeing. It was conducted in direct response to concerns about racial discrimination related to COVID-19 raised by young people.

The CMY Racism During COVID-19 Survey was a community-based, cross-sectional online survey completed participants aged 16-24 years in Victoria. The survey was not designed to be a representative sample, rather, the intention was to engage with members in the CMY network to better understand the experiences of the young Victorian's that CMY engages and supports. Therefore, a convenience sampling strategy was used and participants were recruited through CMY's networks via social media and their monthly newsletter. Anonymous data was collected between June 5 and June 28 2020, using Survey Monkey.

Ethics approval was obtained from the Australian National University Human Ethics Committee (2020/376) for the analysis of this data. CMY provided de-identified data to the ANU researchers (NP, KD). 


\subsection{Measures}

Participants were asked about experiences of direct discrimination, vicarious racial discrimination, heightened vigilance, worries about experiencing racial discrimination in their public life, COVID-19 related stressors and mental health problems. These measures are summarised below and detailed in full in Supplementary File Table A.

\subsubsection{Direct experiences of discrimination}

Participants personal experiences of direct discrimination was measured using eleven items adapted from the Adolescent Discrimination Distress Index[38] previously used in Australia.[39] Participants were asked how often they had experiences of direct discrimination, including being called names, left out of activities or hassled by the police since the COVID19 crisis began. For example, 'Since the COVID-19 crisis began how often: Were you called insulting names by others?'. Frequency was reported from $0={ }^{'}$ Never, 1='Once or twice', 2='Every few weeks', 3='About once a week', to 4='Several times a week or more'. A binary response, 'Yes, at least once' versus 'Never', was created for each direct discrimination item. A direct discrimination scale was derived by taking the mean of responses across the eleven items (Cronbach's $\alpha=0.92$ ), with higher scores indicating more direct discrimination.

\subsubsection{Vicarious racial discrimination}

Participants experiences of vicarious racial discrimination were measured using four items adapted from the Online Victimization Scale for Adolescents as previously used.[39, 40] Participants were asked how often they had been treated unfairly online or witnessed others being treated unfairly due to their racial, ethnic or cultural group since the COVID-19 crisis began. For example, 'Since the COVID-19 crisis began how often have the following things happened: People have made jokes about people of my racial, ethnic or cultural group online or in the media.' Frequency was reported from $0={ }^{\circ}$ Never', $1=$ 'Less than once a year', $2={ }^{\text {'Less }}$ than once a month', 3='A few times a month', 4='At least once a week', 5='Almost everyday'. A binary response, 'Yes, at least once' versus 'Never', was created for each item. A vicarious racial discrimination scale was derived by taking the mean of responses across these four items (Cronbach's $\alpha=0.82$ ), with higher scores indicating more vicarious racial discrimination.

\subsubsection{Heightened vigilance}

Heightened vigilance was measured using four items adapted for Australia/COVID-19 from the Chicago Community Adult Health Study.[41] Participants were asked how often they had prepared for insults, been careful about their appearance, watched what they said or tried to avoid certain situations and places since the COVID-19 crisis began. For example, 'Since the 
COVID-19 crisis began how often you have done the following things: Tried to prepare for possible insults from other people before leaving home.' Frequency was reported from $0=$ 'Never', 1='A few times', 2='At least once a week', 3='Almost everyday'. A binary response, 'Yes, at least once' versus 'Never', was created for each item. A heightened vigilance scale was derived by taking the mean of responses across these four items (Cronbach's $\alpha=0.83$ ), with higher scores indicating higher vigilance.

\subsubsection{Worries about experiencing racial discrimination}

Interlinked with heightened vigilance, participants were asked about their worries concerning racism and or discrimination as Victoria exited out of lockdown. These four items were developed for this survey by CMY based on feedback from their networks. Participants were asked, 'As we return to more daily activities, how worried are you about facing racism and/or discrimination in the following settings: school or study, work or training, sport or recreation, and in public spaces.' Participants' level of worry was reported from: $0=$ 'Not at all', 1='Slightly', 2='Somewhat', 3='Very', 4='Extremely'. A binary response variable ('Somewhat/ Slightly/ Very/ Extremely Worried' versus 'Not at all worried') was created for each item. A worries scale was derived by taking the mean of responses across these four items (Cronbach's $\alpha=0.90$ ), with higher scores indicating greater worries about experiencing racial discrimination.

\subsubsection{COVID-19 Related Stressors}

Changes to everyday life throughout the COVID-19 crisis was assessed using an eleven item measurement, adapted from the CoRonavIruS Health Impact Survey (CRISIS) survey.[42] These items asked participants if COVID-19 and associated restrictions had increased their stress in relation to leaving the house, exercising, financial situation, accessing services and on their relationships with friends and family. For example, participants were asked, 'how difficult has it been to access the supports and services (e.g. Centrelink/income support or health services) to meet your and/or your families needs?' Responses were scored on a 0-4 point scale with a higher number associated with a more negative impact on daily life (Cronbach's $\alpha=$ $0.61)$.

Responses were recoded to create a binary variable ( $0-2$ versus $3-4)$. These binary scores were used to create a summary three-category variable of the total number of stressors $(0-11$ stressors) with results presented as '0 stressors', '1-2 stressors' and '3 or more' stressors. A 
binary summary variable was also created for further analysis, with results presented as ' $0-2$ stressors' and ' 3 or more stressors'.

\subsubsection{Mental Health problems}

Emotions and worry in the previous two weeks were assessed using an eight item measurement, adapted from the CRSIS Survey.[42] These items were all scored on a 0-4 point scale with a higher number associated with more negative emotions/increased worry. For example: 'How worried were you generally?' response options were: 'Not worried at all'; 'Slightly worried; 'A bit worried'; 'Very worried'; and 'Extremely worried' (Cronbach's $\alpha=0.84$ ).

Responses were recoded to create a binary variable 'Low distress (low/Very low) $=0$, 'High distress $($ Moderate/High/Very High) $=1$. These binary variables were combined to create two summary count variables of the total number of mental health problems $(1+$ high distress $)$ and $(2+$ high distress $)$ to be used for descriptive analysis and community feedback. For use in regression analysis, a continuous mental health scale was derived by adding the total score across all eight items (range 0-32), with a higher score indicating higher mental health problems in line with Priest et al. 2020.[19]

\subsubsection{Covariates}

Participants were asked to self-report their own racial, ethnic, or cultural backgrounds, with the option of selecting multiple categories. This ethnicity item and the corresponding response categories were developed for the Speak Out Against Racism survey.[39] Self-reported ethnicity is not routinely collected in Australia, and therefore there are no standard classifications available. Ethnicity was coded as 'Aboriginal and/or Torres Strait Islander', 'Anglo/European', and 'Multicultural Backgrounds'. Following international guidelines,[4345] ethnicity was coded using a prioritisation method whereby the Anglo-European ethnicity coding does not include people who also identified as being from multiple ethnic/racial/cultural backgrounds. We recognise the considerable diversity among multicultural and ethnic minority groups, and that collapsing these groups in one larger category for statistical analysis has limitations.[46]

Two questions were used to determine how many generations' participants had been in Australia. Participants were asked in what country they were born, which was coded as a binary outcome of 'Born in Australia' or 'Born overseas'. Participants who were born in Australia were asked if their parents were born in Australia. These two items were used to determine if participants were first generation (born overseas), second generation (born in Australia with at 
least one parent born overseas), or at least third generation Australian (participants and parents born in Australia).[47] Participants who were born overseas were asked, 'when did you arrive in Australia?' This variable was coded as 'Less than five years', 'Five to ten years', and 'More than ten years'.

Participants were asked which language they spoke at home and were able to select multiple options with the variable coded as 'English only', 'English and a second language', and 'language other than English only'.

Participants self-reported their gender (male, female, other); date of birth and postcode. Participants' age was calculated from their date of birth and the date of initial analysis with age categorised as 'Under 18' and 'Over 18'. Participants' Socio-Economic Indexes for Areas (SEIFA) was determined using Australian Bureau of Statistics Index of Relative Socioeconomic Disadvantage, distribution on the SEIFA index was scored using the postcodes percentile ranking within Australia with low scores indicating higher levels neighbourhood disadvantage. [48] Participants' SEIFA was classified as being in the 'top 75 percentiles' or 'bottom 25 percentile'.

\subsection{Statistical analysis}

Participants above or below the target demographic of 16-24 years of age were excluded from analysis $(n=14)$. Descriptive analyses were used to estimate the prevalence of racism, discrimination, COVID-19 related stressors and mental health problems as well as key sociodemographics by ethnicity, in this sample. To address the second and third research aims to examine associations between self-reported ethnicity and experiences of discrimination and the number of COVID-19 related stressors, and to examine associations between discrimination, COVID-19 related stressors and mental health problems a series of regression models were fitted. Prevalence rate ratios were calculated using Poisson Regressions with a robust variance estimator as recommended when the outcome is not rare (>10\%).[49] Poisson regression was used to examine associations between self-reported ethnicity and the number of COVID-19 related stressors ( $0-2$ versus 3 or more). A series of linear regression models were used to examine associations between ethnicity and each of the discrimination measures. Another series of linear regression models explored association between discrimination measures and COVID-19 related stressors with mental health problems. Models were adjusted for gender, ethnicity (where applicable), age and SEIFA. 
The proportion of participants with missing data in any of the analysis variables was $47 \%$. There was a high degree of missing data on the exposure and outcomes, with $34 \%$ having missing data on at least one subscale (direct discrimination $31 \%$; vicarious racial discrimination $28 \%$; heightened vigilance $30 \%$; worries about experiencing racial discrimination $32 \%$; COVID-19 related stressors 16\%; mental health problems 26\%). For patterning of missing data by covariates, see Supplementary File Table B. To reduce the potential for selection bias due to the high degree of missingness, multiple imputation by chained equations was conducted, using linear regression models for continuous variables and logistic regression models for binary variables.[50] 50 imputed datasets were generated replacing missing data with plausible imputed data. All results are presented using the imputed dataset (imputed sample, $n=363$ ), with non-imputed results included in Supplementary File Tables C \& D. All analysis was conducted in Stata V.16.[51]

\section{Results}

\subsection{Sample characteristics}

The analysis sample included $n=363$ young people, of which $50.9 \%$ (95\% Confidence Interval (CI) (45.6 to 56.1) self-identified as being from an Anglo/European background (AngloCeltic', 'European- Southern', 'European- Northern/Western/Eastern'), 45.4\% (95\% CI 40.2 to 50.7) from a multicultural background ('East Asian', 'Southeast Asian', 'South Asian', 'Middle Eastern', 'Pacific Islander', 'Northern African', 'Southern African') and 3.7\% (95\% CI 1.7 to 5.7) as Aboriginal and/or Torres Strait Islander.

Table 1 shows that two thirds of the participants were female (65.7\% (95\% CI 60.8 to 70.6$)$ ) and born in Australia (63.8\% (95\% CI 58.8 to 68.8)), and just over half the participants only spoke English at home (55.3\% (95\% CI 50.2 to 60.5)). Of the participants who self-identified as being from an Anglo/European backgrounds, the majority (95.8\% (95\% CI 92.8 to 98.9)) were born in Australia, with 82.8\% (95\% CI 77.1 to 88.4) being at least third generation Australian. Of participants who self-identified as being from a multicultural background, $75.2 \%$ (95\% CI 68.3 to 82.0 ) were first generation Australians, born overseas, with $44.0 \%$ (95\% CI 35.0 to 53.0) arriving in Australia in the last five years. All of the participants who self-identified as being Aboriginal and/or Torres Strait Islander were born in Australia, with the majority (89.1\% (95\% CI 67.1 100.0) being at least third generation Australian. 


\subsection{Prevalence of direct discrimination, vicarious racism, heightened vigilance, worries}

about experiencing racial discrimination, COVID-19 related stressors and mental health problems in young multicultural Victorians during lockdown

Racism and Discrimination: Most participants reported experiences of direct discrimination (73.7\% (95\% CI 68.2 to 79.2$))$ and vicarious racial discrimination (88.9\% (95\% CI 85.0 to 92.7) as well as heightened vigilance (84.3\% (95\% CI 79.8 to 88.8)) and worries about experiencing racial discrimination in public life (62.8\% (95\% CI 56.7 to 68.8)) (See Table 1).

Participants who self-identified as Aboriginal and/or Torres Strait Islander or from a multicultural background had higher rates of experiences of discrimination, reporting higher average scores across all four discrimination subscales compared to participants from an Anglo/European background.

While high rates of direct and vicarious racial discrimination were documented across the sample, very few young people reported these experiences to others at the time. Of the participants who responded to the item asking about actions tacking following their experience $(n=225), 58.7 \%$ of participants ignored it, while $6.2 \%$ reported it, $28.4 \%$ talked about it with friends and family, and $7.1 \%$ told a teacher or health professional (see Supplementary File Table E).

Table 1. Sample characteristics overall and by ethnicity (imputed samples, $n=363$ )

\begin{tabular}{|c|c|c|c|c|}
\hline & Anglo/Euro & $\begin{array}{l}\text { Multicultural } \\
\text { Backgrounds }\end{array}$ & $\begin{array}{c}\text { Aboriginal and/or } \\
\text { Torres Strait Islander }\end{array}$ & Total \\
\hline & $\begin{array}{l}\%(95 \% \mathrm{CI}) \text { or } \\
\text { mean }(95 \% \mathrm{CI})\end{array}$ & $\begin{array}{l}\%(95 \% \mathrm{CI}) \text { or } \\
\text { mean }(95 \% \mathrm{CI})\end{array}$ & $\begin{array}{l}\%(95 \% \mathrm{CI}) \text { or } \\
\text { mean }(95 \% \mathrm{CI})\end{array}$ & $\begin{array}{l}\%(95 \% \mathrm{CI}) \text { or } \\
\text { mean }(95 \% \mathrm{CI})\end{array}$ \\
\hline Socio-demographics & $50.88(45.62,56.14)$ & $45.41(40.17,50.65)$ & $3.71(1.735 .68)$ & \\
\hline \multicolumn{5}{|l|}{ Gender } \\
\hline Male & $33.51(26.57,40.46)$ & $31.74(24.48,39.00)$ & $23.46(0.00,49.70)$ & $32.34(27.50,37.17)$ \\
\hline Female & $63.89(56.82,70.96)$ & $66.89(59.56,74.22)$ & $76.54(50.30,100.00)$ & $65.72(60.81,70.63)$ \\
\hline \multicolumn{5}{|l|}{ Age } \\
\hline Under 18 & $47.24(38.46,56.02)$ & $38.34(27.55,49.12)$ & $35.67(0.00,78.71)$ & $42.77(35.89,49.65)$ \\
\hline Over 18 & $52.76(43.98,61.54)$ & $61.66(50.88,72.45)$ & $64.33(21.29,100.00)$ & $57.23(50.35,4.12)$ \\
\hline \multicolumn{5}{|l|}{ Country of birth } \\
\hline Australia & $95.82(92.79,98.86)$ & $25.34(18.48,32.20)$ & 100.00 & $63.80(58.83,68.77)$ \\
\hline Overseas & $4.18(1.14,7.21)$ & $74.66(67.80,81.52)$ & - & $36.20(31.23,41.17)$ \\
\hline \multicolumn{5}{|l|}{ Generation in Australia } \\
\hline 1st Generation ${ }^{1}$ & $4.47(1.24,7.69)$ & $75.15(68.30,82.00)$ & - & $36.59(31.59,41.59)$ \\
\hline 2nd Generation ${ }^{2}$ & $12.75(7.82,17.67)$ & $22.40(15.91,28.89)$ & $10.90(0.00,32.89)$ & $17.04(13.13,20.95)$ \\
\hline$\geq$ 3rd Generation ${ }^{3}$ & $82.79(77.14,88.43)$ & $2.46(0.00,5.54)$ & $89.10(67.11,100.00)$ & $46.37(41.19,51.55)$ \\
\hline \multicolumn{5}{|c|}{ Length of time in Australia (If born Overseas) } \\
\hline$<5$ Years & $39.15(0.00,96.54)$ & $44.04(35.03,53.04)$ & - & $43.75(35.07,52.43)$ \\
\hline $5-10$ years & $31.49(0.00,85.59)$ & $27.14(19.08,35.20)$ & - & $27.39(19.59,35.19)$ \\
\hline$\geq 10$ years & $29.36(0.00,80.47)$ & $28.82(20.62,37.03)$ & - & $28.86(20.94,36.78)$ \\
\hline \multicolumn{5}{|c|}{ Language Spoken at home } \\
\hline English only & $91.38(87.20,95.56)$ & $12.60(7.20,17.99)$ & $84.27(61.64,100.00)$ & $55.32(50.18,60.45)$ \\
\hline
\end{tabular}




\begin{tabular}{|c|c|c|c|c|}
\hline $\begin{array}{l}\text { English and a } \\
\text { second language }\end{array}$ & $6.93(3.17,10.69)$ & $60.80(53.16,68.45)$ & $15.73(0.00,38.36)$ & $31.71(26.91,36.52)$ \\
\hline $\begin{array}{l}\text { Language other } \\
\text { than English }\end{array}$ & $1.69(0.00,37.2)$ & $26.60(19.75,33.44)$ & - & $12.97(9.50,16.44)$ \\
\hline \multicolumn{5}{|l|}{$S E I F A^{4}$} \\
\hline Top 75 Percentile & $61.84(52.79,70.89)$ & $63.44(53.72,73.15)$ & $54.13(16.82,91.44)$ & $62.28(55.82,68.73)$ \\
\hline Bottom 25 & $38.16(29.11,47.21)$ & $36.56(26.85,46.28)$ & $45.87(8.56,83.18)$ & $37.72(31.27,44.18)$ \\
\hline Percentile & & & & \\
\hline \multicolumn{5}{|l|}{ Rurality } \\
\hline Major City & $37.17(28.81,45.52)$ & $56.66(46.31,67.00)$ & $24.35(0.00,57.44)$ & $45.54(39.04,52.05)$ \\
\hline Regional Victoria & $62.83(54.48,71.19)$ & $43.34(33.00,53.69)$ & $75.65(42.565,100.00)$ & $54.46(47.95,60.96)$ \\
\hline \multicolumn{5}{|c|}{ Mental health problems } \\
\hline $1+$ high distress & $99.30(97.92,100.00)$ & $94.11(88.82,98.39)$ & 100.00 & $97.03(95.07,99.07)$ \\
\hline $2+$ high distress & $93.43(89.28,97.57)$ & $89.48(83.84,95.11)$ & 100.00 & $91.85(88.57,95.13)$ \\
\hline $\begin{array}{l}\text { Mental Health } \\
\text { problems (mean of } \\
\text { total score } 0-32 \text { ) }\end{array}$ & $15.94(14.93,16.94)$ & $14.58(13.52,15.65)$ & $16.64(12.18,21.10)$ & $15.35(14.63,16.06)$ \\
\hline \multirow{2}{*}{\multicolumn{5}{|c|}{$\begin{array}{l}\text { COVID-19 Related } \\
\text { Stressors }\end{array}$}} \\
\hline & & & & \\
\hline 0 Stressors & $14.31(8.77,19.86)$ & $14.98(8.88,21.15)$ & $10.28(0.00,33.06)$ & $14.47(10.50,18.44)$ \\
\hline $1-2$ stressors & $60.25(52.52,67.99)$ & $41.62(33.15,50.10)$ & $39.46(3.45,75.48)$ & $51.32(45.67,56.96)$ \\
\hline $3+$ stressors & $25.43(18.54,32.32)$ & $43.40(34.86,51.93)$ & $50.26(13.27,87.24)$ & $34.21(28.86,39.57)$ \\
\hline \multicolumn{5}{|l|}{ Discrimination } \\
\hline \multicolumn{5}{|l|}{ Direct discrimination } \\
\hline Any Direct & $63.84(55.46,72.22)$ & $85.05(78.27,91.83)$ & $74.79(36.39,100.00)$ & $73.71(68.23,79.18)$ \\
\hline Direct (mean) & $0.29(0.19,0.39)$ & $0.66(0.53,0.80)$ & $0.89(0.33,1.46)$ & $0.48(0.40,0.57)$ \\
\hline \multicolumn{5}{|l|}{ Vicarious racism } \\
\hline Any Vicarious & $85.90(79.88,91.91)$ & $91.58(86.32,96.84)$ & 100.00 & $88.85(85.00,92.69)$ \\
\hline Vicarious (mean) & $1.45(1.24,1.66)$ & $2.69(2.44,2.95)$ & $3.43(2.65,4.21)$ & $2.09(1.91,2.26)$ \\
\hline \multicolumn{5}{|l|}{ Heightened vigilance } \\
\hline $\begin{array}{l}\text { Any Heightened } \\
\text { vigilance }\end{array}$ & $77.53(70.27,84.79)$ & $91.99(86.76,97.21)$ & $85.87(53.15,100.00)$ & $84.25(79.75,88.75)$ \\
\hline $\begin{array}{l}\text { Heightened } \\
\text { vigilance (mean) }\end{array}$ & $0.83(0.69,0.96)$ & $1.34(1.18,1.51)$ & $1.14(0.65,1.63)$ & $1.07(0.97,1.18)$ \\
\hline \multicolumn{5}{|c|}{$\begin{array}{l}\text { Worries about experiencing } \\
\text { racial discrimination }\end{array}$} \\
\hline Any Worries & $38.51(29.83,47.18)$ & $86.66(80.21,93.11)$ & 100.00 & $62.75(56.69,68.81)$ \\
\hline Worries (mean) & $0.46(0.31,0.61)$ & $1.42(1.25,1.59)$ & $1.22(0.60,1.88)$ & $0.92(0.80,1.05)$ \\
\hline
\end{tabular}

Note: Results are presented using multiple imputation to account for missing data. Not all data for the Aboriginal and/or Torres Strait Islander population could be imputed with some response options not selected. ${ }^{1}$ First Generation- Born in Australia; ${ }^{2}$ Second Generation- Born in Australia and parent/s born overseas; ${ }^{3}$ At least third Generation- Born in Australia and both parents born in Australia; ${ }^{4}$ Socio-Economic Indexes for Areas (SEIFA)

COVID-19 Related Stressors: Half (51.3\% (95\% CI 45.7 to 57.0)) of the participants experienced one or two COVID-19 related stressors, with a third (34.2\% (95\% CI 28.9 to 39.6)) reporting at least three stressors. 50.2\% (95\% CI 13.3 to 87.2) of Aboriginal and/or Torres Strait Islander participants, $43.4 \%$ (95\% CI 34.9 to 51.9) multicultural participants and $25.4 \%$ (95\% CI 18.5 to 32.3) Anglo/European participants reported at least three COVID-19 related stressors.

Mental Health problems: We observed high rates of psychological distress in this sample. Almost all 97.0\% (95\% CI 95.1 to 99.1) of the participants reported high levels on at least one item of mental health problems, with $91.9 \%$ (95\% CI 88.6 to 95.1$)$ reporting high levels for 
two or more items. While there were high rates of mental health problems, of the participants who responded to the item asking them if they had reached out for support for emotional wellbeing ( $\mathrm{n}=263)$, less than half $(45.6 \%)$ reported receiving support from friends, family or from a professional/service, with only $12.2 \%$ of participants receiving professional help (see Supplementary File Table E).

\subsection{Associations between self-reported ethnicity and experiences of discrimination and the number of COVID-19 related stressors}

After adjusting for gender, age and SEIFA, we found strong evidence that experiences of direct discrimination, vicarious racial discrimination and worrying about experiences of racial discrimination, were associated with ethnicity, with experiences of heightened vigilance showing some association for participants from multicultural backgrounds, but not for participants who self-identified as being Aboriginal and/or Torres Strait Islander (Table 2). Self-identifying as being from a multicultural background was associated with an increase of $0.4(95 \%$ CI 0.2 to 0.6$)$ in the mean score of direct discrimination and an increase of $1.2(95 \%$ CI 0.9 to 1.6) in the mean score of vicarious racial discrimination. Self-identifying as Aboriginal and/or Torres Strait Islander was associated with an increase of 0.7 (95\% CI 0.2 to 1.1 ) in the mean score of direct discrimination, and an increase of 2.0 (95\% CI 1.1 to 2.9) in the mean score of vicarious racial discrimination. Being from a multicultural background was associated with an increase of 1.0 (95\% CI 0.7 to 1.2) and self-identifying as being Aboriginal/Torres Strait Islander was associated with a 0.8 (95\% CI 0.1 to 1.4$)$ in the mean score of worries about experiencing racial discrimination when returning to public life. Being from a multicultural background was associated with an increase of 0.5 (95\% CI 0.3 to 0.7$)$ in the mean score of heightened vigilance, while there was no evidence of association for Aboriginal and/or Torres Strait Islander participants.

As shown in Table 2, there was evidence to suggest that ethnicity was associated with an increase in the number of COVID-19 related stressors. Multicultural youth were 1.7 (95\% CI 1.1 to 2.5 ) times more likely to report three or more COVID-19 related stressors compared to participants from Anglo/European backgrounds, while Aboriginal and/or Torres Strait Islander youth were 1.7 (95\% CI 0.7 to 4.1$)$ times more likely to experience three or more COVID-19 related stressors. 

problems

As shown in table 3 there was evidence of an association between increased experiences of racial discrimination and negative mental health problems after adjusting for ethnicity, age, gender and SEIFA. Linear regression results showed a 1.6 (95\% CI 0.5 to 2.8$)$ increase in the mental health problems score for every increase in the mean score for experiences of direct discrimination. There was a $1.2(95 \%$ CI 0.6 to 1.8$)$ increase in the mental health problems score for every increase in the mean score of experiences of vicarious racial discrimination. 
Table 2. Unadjusted and adjusted regression results for the associations between ethnicity and racial discrimination and stressor experiences during COVID-19 pandemic (imputed sample, $n=363$ )

\begin{tabular}{|c|c|c|c|c|c|c|c|c|c|c|}
\hline & \multicolumn{2}{|c|}{ Direct racial discrimination } & \multicolumn{2}{|c|}{ Vicarious racial discrimination } & \multicolumn{2}{|c|}{ Heightened vigilance } & \multicolumn{2}{|c|}{$\begin{array}{l}\text { Worry about experiencing } \\
\text { racism }\end{array}$} & \multicolumn{2}{|c|}{ COVID-19 related stressors } \\
\hline & $\begin{array}{c}\text { Unadjusted } \\
\text { Coeff }(95 \% \\
\text { CI })\end{array}$ & $\begin{array}{c}\text { Adjusted \# } \\
\text { Coeff }(95 \% \\
\text { CI })\end{array}$ & $\begin{array}{c}\text { Unadjusted } \\
\text { Coeff }(95 \% \\
\text { CI })\end{array}$ & $\begin{array}{c}\text { Adjusted \# } \\
\text { Coeff }(95 \% \\
\text { CI) }\end{array}$ & $\begin{array}{c}\text { Unadjusted } \\
\text { Coeff }(95 \% \\
\text { CI })\end{array}$ & $\begin{array}{l}\text { Adjusted \# } \\
\text { Coeff }(95 \% \\
\text { CI })\end{array}$ & $\begin{array}{c}\text { Unadjusted } \\
\text { Coeff }(95 \% \\
\text { CI })\end{array}$ & $\begin{array}{c}\text { Adjusted \# } \\
\text { Coeff }(95 \% \\
\text { CI })\end{array}$ & $\begin{array}{c}\text { Unadjusted } \\
\text { Exp (b) }(95 \% \\
\text { CI) }\end{array}$ & $\begin{array}{c}\text { Adjusted \# } \\
\text { Exp (b) }(95 \% \\
\text { CI) }\end{array}$ \\
\hline $\begin{array}{l}\text { Multicultural } \\
\text { backgrounds }\end{array}$ & $\begin{array}{c}0.38(0.21 \\
0.54)\end{array}$ & $\begin{array}{c}0.40(0.24 \\
0.56)\end{array}$ & $\begin{array}{c}1.24(0.91 \\
1.58)\end{array}$ & $\begin{array}{l}1.22(0.89 \\
1.55)\end{array}$ & $\begin{array}{l}0.52(0.30 \\
0.74)\end{array}$ & $\begin{array}{c}0.53(0.31 \\
0.74)\end{array}$ & $\begin{array}{c}0.96(0.74 \\
1.18)\end{array}$ & $\begin{array}{c}0.96(0.74 \\
1.18)\end{array}$ & $\begin{array}{l}1.72(1.16, \\
2.54)\end{array}$ & $\begin{array}{l}1.65(1.11 \\
2.45)\end{array}$ \\
\hline $\begin{array}{l}\text { Aboriginal and/or } \\
\text { Torres Strait } \\
\text { Islander }\end{array}$ & $\begin{array}{c}0.61(0.16 \\
1.06)\end{array}$ & $\begin{array}{c}0.68(0.23 \\
1.12)\end{array}$ & $\begin{array}{c}1.98(1.11 \\
2.85)\end{array}$ & $\begin{array}{c}1.98(1.10 \\
2.85)\end{array}$ & $\begin{array}{c}0.31(-0.24 \\
0.87)\end{array}$ & $\begin{array}{c}0.32(-0.25 \\
0.88)\end{array}$ & $\begin{array}{c}0.76(0.11 \\
1.42)\end{array}$ & $\begin{array}{c}0.77(0.13 \\
1.41)\end{array}$ & $\begin{array}{c}1.86(0.77 \\
4.48)\end{array}$ & $\begin{array}{c}1.68(0.70, \\
4.08)\end{array}$ \\
\hline Anglo/European & 1 (ref) & 1 (ref) & 1 (ref) & 1 (ref) & 1 (ref) & 1 (ref) & 1 (ref) & 1 (ref) & 1 (ref) & 1 (ref) \\
\hline
\end{tabular}

\# Adjusted for Gender, Age \& SEIFA. (Socio-Economic Indexes for Areas).

Table 3 Unadjusted and adjusted associations between discrimination and stressors with mental health problems (imputed sample, $\mathrm{n}=363$ )

\begin{tabular}{lll}
\hline & $\begin{array}{c}\text { Unadjusted } \\
\text { Coeff }(95 \% \mathrm{CI})\end{array}$ & $\begin{array}{c}\text { Adjusted \# } \\
\text { Coeff }(95 \% \mathrm{CI})\end{array}$ \\
\hline $\begin{array}{l}\text { Direct discrimination } \\
\text { Vicarious racial }\end{array}$ & $1.12(0.07,2.17)$ & $1.57(0.51,2.80)$ \\
discrimination & $0.81(0.30,1.33)$ & $1.21(0.61,1.81)$ \\
$\begin{array}{l}\text { Heightened vigilance } \\
\text { Worry about }\end{array}$ & $1.38(0.53,2.24)$ & $1.80(0.91,2.70)$ \\
$\begin{array}{l}\text { experiencing racism } \\
\text { COVID-19 related }\end{array}$ & $1.08(0.34,1.82)$ & $1.76(0.90,2.62)$ \\
stressors & $3.99(2.57,5.40)$ & $4.36(2.89,5.84)$ \\
\hline
\end{tabular}

\# Adjusted for Ethnicity, Gender, Age \& SEIFA. 
Not only were experiences of discrimination associated with increases in mental health problems, but worrying about experiencing racial discrimination in public spaces and feeling the need to change behaviour to not experience discrimination (heightened vigilance) were also associated with an increase in poor mental health problems. There was a 1.8 (95\% CI 0.9 to 2.7) increase in the mental health problems score for every increase in the mean score of experiences of heightened vigilance, and an increase of 1.8 (95\% CI 0.9 to 2.6) in the mental health score for every increase in the mean worries score after adjusting for ethnicity, gender, age and SEIFA.

In addition, participants who experienced three or more stressors due to COVID-19 saw an increase of 4.4 (95\% CI 2.9 to 5.8) in their mental health problem score after adjusting for ethnicity, gender age and SEIFA.

\section{Discussion}

This cross-sectional study investigated young people's experiences of discrimination, racism, COVID-19 related stressors and their impact on mental health problems during the 2020 COVID-19 pandemic lockdown in Victoria, Australia. This study showed that young Victorians who self-identified as Aboriginal and/or Torres Strait Islander or as being from a multicultural background reported higher rates of discrimination and COVID-19 related stressors compared to their non-Indigenous, non-racialised peers. There was clear evidence indicating that young people with experiences of racism, discrimination and high COVID-19 related distress were at risk of more negative mental health problems during the lockdown.

Findings from this research align with other research showing that young people from diverse cultural backgrounds experience high rates of discrimination and racism outside of the current COVID-19 context.[52] Previous research in Australia conducted with a younger sample in the Speak Out Against Racism (SOAR) study, showed that of the 4,664 students aged 10-15, 42\% experienced direct racial discrimination; with participants form an Anglo and European background experiencing the lowest rate of direct discrimination (25\% Anglo; 38\% European); with participants form multicultural backgrounds experiencing higher rate (for example 59\% South East Asian; 62\% Middle Eastern; and 58\% African), in addition participants form Indigenous backgrounds also experienced high rates (50\%).[19] 70\% of participants from the SOAR study experienced vicarious racial discrimination with participants who self-identified as being Aboriginal and/or Torres Strait Islander experienced higher levels of vicarious 
discrimination than participants form European and Anglo backgrounds (72\% Aboriginal and/or Torres Strait Islander; 71\% European; 68\% Anglo).[19] Experiences of vicarious discrimination varied for participants from multicultural backgrounds (for example: 66\% Middle Eastern; 83\% African; and 77\% pacific Islander / Maori).[19]

Similarly, a recent longitudinal study of 1,147 children and youth in the Project on Human Development in Chicago Neighborhoods showed that African American and Hispanic youth experienced higher rates of racial discrimination, vicarious racial discrimination and anticipated discrimination compared to white youth.[53] Consistent with previous findings with Asian Australians[54], American Filipinx adults,[55] and Chinese families,[56] our findings show that experiences of discrimination and racism may be at increased levels due to the global pandemic. A recent study conducted with Asian-Australians $(n=2,003)$ found that 45\%-53\% of Asian Australians aged 16-24 years experienced racism in the COVID-19 context.[54] Cheah et al. (2020) reported that $50 \%$ of the 230 children included in their study experienced direct in person racial discrimination, 92\% experienced vicarious racial discrimination in person and $77 \%$ witness vicarious racial discrimination online.[56] The high prevalence of racism and racial discrimination in the COVID-19 context highlights the necessity of addressing this public health concern.

This study extends current understanding of racism and racial discrimination by adding another two measures of racism related vigilance and worries about experiencing racial discrimination, which have not been previously captured among Australian young people. To our knowledge, this is the first study to explore heightened vigilance with a diverse youth population in Australia. Results from this study are supported by a recent study of black adolescents in the United States $(\mathrm{N}=442$ aged 14-17), which found that young people had higher rates of experiences of racism and a higher degree of racism related anticipatory stress, including expecting further experiences.[57] Kamp et al. (2021) also found that 80\% of Asian Australians worried about experiencing racial discrimination, and 77\% reported they avoided situations due to racism.[54] Using these different dimensions of racism is useful to capture the varying impact that racism can have on individuals.

We found clear evidence that experiences of direct discrimination and vicarious racial discrimination were associated with negative mental health problems. This is consistent with multiple studies conducted in Australia and globally that document associations between negative mental health problems and experiences of racial discrimination for children and 
young people.[2, 19] Results from this study are supported by findings from the SOAR Survey, which showed strong evidence that vicarious experiences of racism were related to mental health and socioemotional problems, for example, every increase in the frequency of vicarious racial discrimination was associated with an increase of $0.69(95 \%$ CI $0.58,0.80)$ in emotional symptoms.[19] International findings regarding associations between vicarious racism and depression remain mixed, this may be due to heterogeneous use of vicarious racism measures, age and background of study participants, and respondent reporting the vicarious exposure.[20, 58] Results from our study are consistent with research conducted in the United States with Latinx college students ( $\mathrm{N}=194$ aged 13-34 years) whereby racism related vigilance was correlated with an increase in depressive symptoms.[24] Zimmerman and Miller-Smith (2021) reported that there was an association between experiences of discrimination, and anticipation of discrimination were significantly associated with self-reported depression, while there was no association reported for vicarious racial discrimination.[53] Further attention to the health effects of racism related vigilance among young people is needed, and to addressing this as a key way in which racism impacts on health.

The COVID-19 pandemic continues to have a significant impact on young people around the world, with public health measures to control the pandemic having a negative impact on children and young peoples' health. Our results showed that over half of our participants experienced one or two COVID-19 related stressors, and a third experienced at least three. Results from a national survey conducted by UNICEF Australia, in July and August 2020 $(n=1,289$ aged 13-17), showed that a significant number of young Australians were impacted by the COVID-19 pandemic were experiencing similar stressors to those that were examined in this study.[59] $42 \%$ of young people nationally and 47\% of Melbournians were worried about their friends or family members contracting COVID-19; $63 \%$ of young people nationally and $78 \%$ in Melbourne had to stop seeing their friends; $24 \%$ of young people's parent/s or carers had lost all of part of their income; and $26 \%$ stated they were worried about family income.[59] A review article conducted by Suarez-Lopez et al. (2021) supports our findings by highlighting some of the significant impacts that COVID-19 restrictions have had on the everyday lives of young people living in the United States and that these changes have disproportionately affected children from multicultural backgrounds who are more likely to be impacted by pre-pandemic structural racism.[33] 
Our findings showed that the COVID-19 pandemic significantly impacted young Victorians with experiences of COVID-19 related stressors correlated with mental health problems. A previous study conducted at a national level showed that psychological distress among young Australians', aged 18-24 years, had significantly increased between February 2017 and April 2020.[60] Our results are consistent with international adolescent research conducted in Canada and China, which showed a correlation between the COVID-19 pandemic and mental health problems.[61] Research conducted in China demonstrated that changes to daily life due to the pandemic were associated with mental health problems in an adult population.[62, 63] These results show that more needs to be done to support young people throughout the global COVID-19 pandemic.

\subsection{Strengths and Limitations}

This study explored the experiences of young Australians from multicultural backgrounds during the COVID-19 pandemic. The Racism During COVID Survey was conducted as a snapshot in time and reflects the impacts of the pandemic on young Victorians up till June 2020. The COVID-19 pandemic has lasted longer than ever anticipated, with Victoria, Australia enduring three waves of COVID-19 and six different periods of lockdowns between March 2020-October 2021. The pandemic has had and will have lasting impacts on populations.

The Racism During COVID Survey was not conducted to be a representative sample of young people living in Victoria. This study was conducted as a rapid response in-house service improvement survey with the sample targeted through CMY's monthly newsletter and social media, in order to reach young people connected within their community and with CMY. Due to the nature of the survey and the target audience, the survey is likely to have disproportionately attracted young people who had experiences or were concerned about racism and discrimination throughout the COVID-19 pandemic, which has been demonstrated in our results by high rates of experiences. The recruitment methods may have contributed to the low numbers of Aboriginal and/or Torres Strait Islander participants as CMY does not directly work with Aboriginal and/or Torres Strait Islander communities, for which there are specific youth-focused organisations. In addition, the high response rates from participants' from an Anglo/European background could be due to a desire to take action in the wake of the BLM movement, while there could have been a lower rate of participation from participants from multicultural backgrounds due to mental fatigue caused by the BLM movement. Further 
information and reflection about experiences of racial discrimination and its impacts is needed to inform future service delivery and advocacy work across Australia.

Due to the relatively small sample size, to effectively conduct statistical analysis self-identified ethnicity was collapsed into three categories: Aboriginal and/or Torres Strait Islander, Anglo/European or multicultural backgrounds. In doing so acknowledge that participants from different ethnic or cultural backgrounds do have different experiences with racism and discrimination. There was limited responses from participants who self-identified as being Aboriginal and/or Torres Strait Islander and therefore some results were unable to be imputed.

The Racism During COVID Survey adapted items from the Adolescent Discrimination Distress Index,[38] however, unlike previous use in Australia, this survey did not ask participants if their experiences of direct discrimination were due to their race, ethnicity or cultural group and therefore represents discrimination as a whole and not just racial discrimination. This approach may have resulted in an overestimate of the prevalence of discrimination compared to other measures that attribute experiences to race, ethnicity or cultural group.

This survey also used a number of items that were adapted from the CRISIS Survey,[42] developed in the United States. To our knowledge, this is the first time these measures have been used with a diverse population of young Australians. In addition, the CRISIS Survey consists of an adult form (over 18 Years) and a youth form (16-18 years), items used in this survey were used across both forms. Different studies have used the CRISIS Survey in different ways, for this study only a subset of items were used and were combined to form subscales. While there has been validation of the CRISIS Survey as a whole, there has been limited validation of specific items, and none has been conducted on the subscales and scoring used throughout this study. Further validation of the CRISIS Survey and subset of items is needed in Australia and with a diverse population, in addition, further validation and analysis is needed on the use of these items with a younger sample.

\subsection{Implications}

This research provides valuable insight into the impact that the COVID-19 pandemic has had thus far on young people living in Victoria as they were going through one of the world's longest and toughest lockdowns. Further research is needed to better understand young people's experiences throughout the COVID-19 pandemic and the impact that racism is having on their mental health. For example, exploring the causal mechanism linking racism and mental 
health problems in young people, exploring some buffering factors that may reduce the impact of racism on mental health problems.

While experiences of racism and discrimination are high in our sample, there is a low rate of talking about or reporting experiences. We found a significant lack of reporting of experiences of racism and discrimination in Victoria (only $6 \%$ of participants reported their experience and $7 \%$ talked about their experiences with a teacher, health professional or other worker, and $28 \%$ talked about it with a friend or family member). Similarly, despite high levels of experiences of racism and discrimination, and associations with mental health problems, young people are not talking to friends, family, teachers or health care professionals about their experiences, or seeking support for their social and emotional wellbeing. Further engagement with young people is needed to explore enablers and barriers for help seeking behaviours and to co-design appropriate and effective solutions to address racism and reporting systems.[64]

\section{Conclusion}

This study of youth from Victoria, Australia, highlights the detrimental effect that the COVID19 pandemic is having on a diverse population of young people in Australia. This study has shown the lives of young people has been impacted by the pandemic and subsequent control measures. We found that young people who self-identified as being Aboriginal and/or Torres Strait Islander or from a multicultural background were more likely to have experienced racism or discrimination and were more likely to have their lives impacted by the COVID-19 pandemic. This study has also showed that experiences of racism and discrimination, and COVID-19 related stressors are associated with negative mental health problems of young people. 


\section{References}

1. Phelan, J.C. and B.G. Link, Is racism a fundamental cause of inequalities in health? Annual Review of Sociology, 2015. 41(311-330). https://doi.org/10.1146/annurev-soc-073014112305 .

2. $\quad$ Priest, N., et al., A Systematic review of studies examining the relationship between reported racism and health and wellbeing for children and young people. Social Science \& Medicine, 2013. 95: p. 115-127. https://doi.org/10.1016/j.socscimed.2012.11.031.

3. Devakumar, D., et al., Racism, the public health crisis we can no longer ignore. Lancet, 2020. 395(10242): p. e112-e113. https://doi.org/10.1016/S0140-6736(20)31371-4.

4. Wendel, M.L., Commentary: Racism is a public health emergency. Family \& Community Health, 2020. 43(4): p. 255-256. https://doi.org/10.1097/FCH.0000000000000281.

5. Godlee, F., Racism: the other pandemic. BMJ, 2020. 369: p. m2303. https://doi.org/10.1136/bmj.m2303.

6. Bartone, T., I. Hickie, and P. McGorry, Joint Statement - COVID-19 impact likely to lead to increased rates of suicide and mental illness. 2020, Australian Medical Asociation: Barton, ACT. Available from: https://ama.com.au/media/joint-statement-covid-19-impact-likely-leadincreased-rates-suicide-and-mental-illness.

7. Australian Indigenous Doctors Association, Indigenous Doctors warn that Racism will Cost Lives. 2020. Available from: https://www.aida.org.au/wpcontent/uploads/2020/03/Indigenous-Doctors-warn-that-racism-will-cost-lives-MEDIARELEASE.pdf.

8. Trent, M., et al., The impact of racism on child and adolescent health. Pediatrics, 2019. 144(2). https://doi.org/10.1542/peds.2019-1765.

9. Walensky, R.P., Media statement from CDC Director Rochelle P. Walensky, MD, MPH, on Racism and health. 2021. Available from: https://www.cdc.gov/media/releases/2021/s0408racism-health.html.

10. Dudgeon, P., et al., A National COVID-19 Pandemic Issues Paper on Mental Health and Wellbeing for Aboriginal and Torres Strait Islander Peoples. Transforming Indigenous Mental Health and Wellbeing Grant. 2020, The University of Western Australia Poche Centre for Indigenous Health: Perth, Australia. Available from: https://apo.org.au/node/306661.

11. Anderson, P. Racism is Killing us: Statement. 2020; Available from: https://www.lowitja.org.au/page/services/policy-and-advocacy/racism-is-killing-us.

12. Bonilla-Silva, E., Rethinking Racism - toward a structural interpretation. American Sociological Review, 1997. 62(3): p. 465-480. https://doi.org/10.2307/2657316.

13. Williams, D.R., Racism and health, in Closing the Gap: Improving the health of minority elders in the new millennium, K.E. Whitefield, Editor. 2004, Gerontological Society of America: Washington DC. p. 69-80.

14. Paradies, Y., Defining, conceptualizing and characterizing racism in health research. Critical Public Health, 2006. 16(2): p. 143-157. https://doi.org/10.1080/09581590600828881.

15. Krieger, N., Discrimination and Health Inequities, in Social Epidemiology, L. Berkman, I. Kawachi, and M.M. Glymour, Editors. 2014, Oxford University Press: New York. https://doi.org/10.1093/med/9780195377903.001.0001

16. Bailey, Z.D., et al., Structural Racism and Health Inequities in the USA: Evidence and interventions. The Lancet, 2017. 389(10077): p. 1453-1463. https://doi.org/10.1016/S01406736(17)30569-X.

17. Jones, C.P., Levels of Racism: A theoretic framework and a gardener's tale. American Journal of Public Health, 2000. 90(8): p. 1212-1215. https://doi.org/10.2105/ajph.90.8.1212.

18. Paradies, Y., et al., Racism as a Determinant of Health: A systematic review and metaanalysis. PLoS One, 2015. 10(9): p. e0138511. https://doi.org/10.1371/journal.pone.0138511.

19. Priest, N., et al., Racial discrimination and socioemotional and sleep problems in a crosssectional survey of Australian school students. Archives of Disease in Childhood, 2020. 105(11): p. 1079-1085. https://doi.org/10.1136/archdischild-2020-318875. 
20. Heard-Garris, N.J., et al., Transmitting trauma: s systematic review of vicarious racism and child health. Social Science \& Medicine, 2017. 199: p. 230-240.

https://doi.org/10.1016/j.socscimed.2017.04.018.

21. Priest, N., et al., Effects over Time of Self-Reported Direct and Vicarious Racial

Discrimination on Depressive Symptoms and Loneliness among Australian School Students.

BMC Psychiatry, 2017. 17(1): p. 50. https://doi.org/10.1186/s12888-017-1216-3.

22. Clark, R., Perceived racism and vascular reactivity in black college women: moderating effects of seeking social support. Health Psychol, 2006. 25(1): p. 20-25.

https://doi.org/10.1037/0278-6133.25.1.20.

23. Hicken, M.T., et al., "Every Shut Eye, Ain't Sleep": The Role of racism-related vigilance in racial/ethnic disparities in sleep difficulty. Race and Social Problems, 2013. 5(2): p. 100-112. https://doi.org/10.1007/s12552-013-9095-9.

24. Pichardo, C.M., et al., Racial Discrimination and Depressive Symptoms among Latina/o College Students: The role of racism-related vigilance and sleep. Race and Social Problems, 2020: p. 1-16. https://doi.org/10.1007/s12552-020-09304-1.

25. Lewis, T., C. Cogburn, and D.R. Williams, Self Reported Expeirences of Discriminatinon and Health: Scientific advances, ongoing controversies, and emerging issues. Annual Review of Clinical Psychology, 2014. 11: p. 10.1-10.34. https://doi.org/10.1146/annurev-clinpsy032814-112728.

26. Sawyer, P.J., et al., Discrimination and the Stress Response: Psychological and physiological consequences of anticipating prejudice in interethnic interactions. American Journal of Public Health, 2012. 102(5): p. 1020-1026. https://doi.org/10.2105/AJPH.2011.300620.

27. LaVeist, T.A., R.J. Thorpe Jr, and G. Pierre, The Relationships among Vigilant Coping Style, Race, and Depression. Journal of Social Issues, 2014. 70(2): p. 241--255.

https://doi.org/10.1111/josi.12058.

28. Lindstrom, M., Social Capital, Anticipated Ethnic Discrimination and Self-Reported Psychological Health: A population-based study. Social Science \& Medicine, 2008. 66(1): p. 1-13. https://doi.org/10.1016/j.socscimed.2007.07.023.

29. Clark, R., R.A. Benkert, and J.M. Flack, Large Arterial Elasticity Varies as a Function of Gender and Racism-Related Vigilance in Black Youth. Journal of Adolescence Health, 2006. 39: p. 562-569. https://doi.org/10.1016/j.jadohealth.2006.02.012.

30. Williams, D.R., J.A. Lawrence, and B.A. Davis, Racism and health: evidence and needed research. Annual Review of Public Health, 2019. 40(1): p. 105-125.

https://doi.org/10.1146/annurev-publhealth-040218-043750.

31. Williams, D.R. and S.A. Mohammed, Discrimination and racial disparities in health: evidence and needed research. J Behav Med, 2009. 32(1): p. 20-47.

https://doi.org/10.1007/s10865-008-9185-0.

32. Department of Health. Coronavirus (COVID-19) Current Situation and Case Numbers. 2021; Available from: https://www.health.gov.au/news/health-alerts/novel-coronavirus-2019-ncovhealth-alert/coronavirus-covid-19-current-situation-and-case-numbers.

33. Suarez-Lopez, J.R., et al., COVID-19 and children's health in the United States: consideration of physical and social environments during the pandemic. Environmental Research, 2021: p. 111160. https://doi.org/10.1016/j.envres.2021.111160.

34. Australian Bureau of Statistics. National, State and Territory Population. 2021; Available from: https://www.abs.gov.au/statistics/people/population/national-state-and-territorypopulation/latest-release.

35. Australian Bureau of Statistics, 2008.0 - Census of Population and Housing: Nature and Content, Australia, 2016. 2017. Available from:

http://www.abs.gov.au/websitedbs/D3310114.nsf/home/Home.

36. Anderson, I., et al., Indigenous and tribal peoples' health (The Lancet-Lowitja Institute Global Collaboration): a population study. The Lancet, 2016. 388(10040): p. 131-157. https://doi.org/10.1016/S0140-6736(16)00345-7.

37. O'Sullivan, D., M. Rahamathulla, and M. Pawar, The Impact and Implications of COVID-19: An Australian perspective. The International Journal of Community and Social Development, 2020. 2(2): p. 134-151. https://doi.org/10.1177/2516602620937922. 
38. Fisher, C.B., S.A. Wallace, and R.E. Fenton, Discrimination distress during adolescence. Journal of Youth and Adolescence, 2000. 29(6): p. 679-695.

https://doi.org/10.1023/A:1026455906512.

39. Priest, N., et al., Findings from the 2017 Speak Out Against Racism (SOAR) Student and Staff Surveys, in CSRM Working Paper Series. 2019, Centre for Social Research and Methods, Australian National University: Canberra, Australia. Available from: https://csrm.cass.anu.edu.au/sites/default/files/docs/2019/9/CSRM-WPSOAR PUBLISH 1 0.pdf.

40. Tynes, B.M., C.A. Rose, and D.R. Williams, The Development and Validation of the Online Victimization Scale for Adolescents. Cyberpsychology: Journal of Psychosocial Research on Cyberspace, 2010. 4(2). https://cyberpsychology.eu/article/view/4237/3282

41. James, S.H., et al., Chicago Community Adult Health Study. 2011, University of Michigan: University of Michigan, Michigan, United States. Available from:

https://www.isr.umich.edu/ccahs/index.html.

42. K. Merikangas, et al., The Coronavirus Health Impact Survey (CRISIS). 2020, National Institute of Mental Health, Bethesda, MD, Johns Hopkins University, Baltimore, MD, Child Mind Institute, New York, NY: United States. Available from: http://www.crisissurvey.org/.

43. Cormack, D. and C. Robson, Classification and output of multiple ethnicities: issues for monitoring Māori health. 2010: Wellington. Available from:

https://www.fmhs.auckland.ac.nz/assets/fmhs/Te\%20Kupenga\%20Hauora\%20M\%C4\%81ori /docs/classification.pdf.

44. Mays, V.M., et al., Classification of Race and Ethnicity: Implications for public health. Annual Review of Public Health, 2003. 24: p. 83-110. https://doi.org/10.1146/annurev.publhealth.24.100901.140927.

45. Agency for Healthcare Research and Quality, Institute of Medicine, Defining Categorization Needs for Race and Ethnicity Data, in Race, Ethnicity, and Language Data: Standardization for health care quality improvement. 2018: Rockville, MD, United States. Available from: https://www.ahrq.gov/research/findings/final-reports/iomracereport/reldata3.html.

46. Khunti, K., et al., The Language of Ethnicity. British Medical Journal, 2020. 371: p. m4493. https://doi.org/10.1136/bmj.m4493.

47. Australian Bureau of Statistics, 2071.0-Census of Population and Housing: Reflecting Australia-stories from the Census, 2016. 2017. Available from:

https://www.abs.gov.au/ausstats/abs@.nsf/Lookup/by\%20Subject/2071.0 2016 Main\%20Fe atures $\sim$ Cultural\%20Diversity\%20Article 60.

48. Australian Bureau of Statistics, Table 2: Postal area (POS) index of relative socio-economic disadvantage, 2016, in 2033.0.55.001 Socio-economic Indexes for Australia (SEIFA), 2016. 2018: Canberra, Australia. Available from: https://www.abs.gov.au/AUSSTATS/abs@.nsf/DetailsPage/2033.0.55.0012016?OpenDocum ent.

49. Zocchetti, C., D. Consonni, and P.A. Bertazzi, Relationship Between Prevalence Rate Ratios and Odds Ratios in Cross-Sectional Studies. International Journal of Epidemiology, 1997. 26(1): p. 220-223. https://doi.org/10.1093/ije/26.1.220.

50. White, I.R., P. Royston, and A.M. Wood, Multiple imputation using chained equations: Issues and guidance for practice. Statistics in Medicine, 2011. 30(4): p. 377-399. https://doi.org/10.1002/sim.4067.

51. StataCorp, Stata Statistical Software: Release 16. 2019, Stata Corp LP: College Station, TX.

52. Sharif, M., et al., Social Patterning of Racial Discrimination Among a Diverse Sample of School-Aged Children in Australia. Journal of Racial and Ethnic Health Disparities, under review. https://doi.org/10.1007/s40615-021-01021-8.

53. Zimmerman, G.M. and A. Miller-Smith, The impact of anticipated, vicarious, and experienced racial and ethnic discrimination on depression and suicidal behavior among Chicago youth. Social Science Research, 2021: p. 102623.

https://doi.org/10.1016/j.ssresearch.2021.102623.

54. Kamp, A., et al., Asian Australians' Experiences Of Racism During The COVID-19 Pandemic. 2021, Centre for Resilient and Inclusive Societies, Deakin University: Melbourne, 
Victoria. Available from:

https://static1.squarespace.com/static/5d48cb4d61091100011eded9/t/60f655dd3ca5073dfd63

6d88/1626756586620/COVID+racism+report+190721.pdf.

55. Maglalang, D.D., et al., Perceived Discrimination and Psychological Distress: A Survey of Filipinx Americans in Massachusetts during the COVID-19 Pandemic. Research Square, 2021. https://doi.org/10.21203/rs.3.rs-502283/v1.

56. Cheah, C.S.L., et al., COVID-19 Racism and Mental Health in Chinese American Families. Pediatrics, 2020. 01: p. 01. https://doi.org/10.1542/peds.2020-021816.

57. Hope, E.C., et al., Black Adolescents'Anticipatory Stress Responses to Multilevel Racism: The role of racial identity. American Journal of Orthopsychiatry, 2021. https://doi.org/10.1037/ort0000547.

58. Tynes, B.M., et al., Online Racial Discrimination and Psychological Adjustment Among Adolescents. Journal of Adolescent Health, 2008. 43(6): p. 565-569. https://doi.org/10.1016/j.jadohealth.2008.08.021.

59. UNICEF Australia, "Swimming with sandbags." The views and experiences of young people in Australia five months into the COVID-19 pandemic. 2020, UNICEF Australia: Sydney, Australia. Available from: https://www.unicef.org.au/our-work/unicef-inemergencies/coronavirus-covid-19/swimming-with-sandbags.

60. Biddle, N., et al., Initial impacts of COVID-19 on mental health in Australia. 2020, ANU Centre for Social Rsearch and Methods. Available from:

https://csrm.cass.anu.edu.au/sites/default/files/docs/2020/6/Mental health before and during the COVID crisis.pdf.

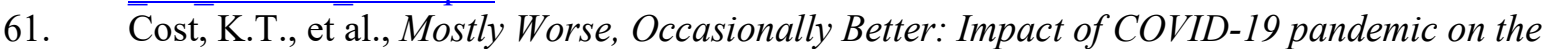
mental health of Canadian children and adolescents. European Child and Adolescent Psychiatry, 2021: p. 1-14. https://doi.org/10.1007/s00787-021-01744-3.

62. Zhu, S., et al., The Immediate Mental Health Impacts of the COVID-19 Pandemic among People with or without Quarantine Managements. Brain, Behavior, and Immunity, 2020. https://doi.org/10.1016/j.bbi.2020.04.045.

63. Zhou, S.-J., et al., Prevalence and Socio-Demographic Correlates of Psychological Health Problems in Chinese Adolescents during the Outbreak of COVID-19. European Child \& Adolescent Psychiatry, 2020. 29(6): p. 749-758. https://doi.org/10.1007/s00787-020-01541-4.

64. Peucker, M., T. Clark, and H. Claridge, All in this together: A community-led response to racism for the City of Wyndham. Final project report. 2021, Victoria University: Melbourne, Australia. Available from: https://www.vu.edu.au/sites/default/files/vu-wyndham-anti-racismproject.pdf. 
Supplementary File Table A. Full details of measures used to assess experiences of discrimination, COVID-19 related stressors and mental health symptoms.

\begin{tabular}{|c|c|c|c|}
\hline Domain & Measure & Item details & Coding in current analysis \\
\hline \multicolumn{4}{|l|}{ Discrimination } \\
\hline Direct Discrimination & $\begin{array}{l}\text { Eleven items } \\
\text { adapted from the } \\
\text { Adolescent } \\
\text { Discrimination } \\
\text { Distress Index } \\
\text { which has } \\
\text { previously used in } \\
\text { Australia in the } \\
\text { Speak Out Against } \\
\text { Racism Survey. }\end{array}$ & $\begin{array}{l}\text { Below are some situations where other people said they were treated } \\
\text { unfairly. We want to know if any of these things have happened to } \\
\text { YOU. (These things could happen to you in person by another person } \\
\text { or a group of people, or online, or using a mobile phone or the internet } \\
\text { such as text messages, pictures, video clips, emails being sent to you or } \\
\text { sent to others, about you. } \\
\text { Since the COVID-19 crisis began how often: } \\
\text { Were you called insulting names by others; Did others leave you out of } \\
\text { their activities; Did people think you didn't speak English well; Did } \\
\text { others spit on you, push you or hit you; Were you threatened by others; } \\
\text { Did you get poor service at a restaurant or fast food place (e.g. being } \\
\text { ignored); Were you treated unfairly by a shop assistant or security } \\
\text { guard; Were you put in a lower ability class at school/uni or given a } \\
\text { lower ability task at work; Were you disciplined unfairly; Were you } \\
\text { given a lower grade or assessment of your work than you deserved; and } \\
\text { Were you hassled by police (or PSOs). } \\
\text { Reponses were scored on a } 5 \text { Point Scale ( } 0=\text { Never; } 1=\text { Once or twice; } \\
2=\text { Every few weeks; } 3=\text { About once a week; and } 4=\text { Several time a } \\
\text { week or more.) }\end{array}$ & $\begin{array}{l}0=\text { Never; } 1=\text { Yes, at least } \\
\text { once } \\
\text { A direct discrimination scale } \\
\text { was derived by taking the } \\
\text { mean of responses across } \\
\text { the eleven items. }\end{array}$ \\
\hline Vicarious discrimination & $\begin{array}{l}\text { Four items adapted } \\
\text { from the Online } \\
\text { Victimization Scale } \\
\text { for Adolescents }\end{array}$ & $\begin{array}{l}\text { Below are some situations where other people said they were treated } \\
\text { unfairly online. We want to know if you have witnessed any of these. } \\
\text { Since the COVID-19 crisis began how often have the following things } \\
\text { happened: } \\
\text { People have made jokes about people of my racial, ethnic or cultural } \\
\text { group online or in the media; People have said things that were untrue } \\
\text { about people of my racial, ethnic or cultural group online or in the }\end{array}$ & $\begin{array}{l}0=\text { Never; } 1=\text { Yes, at least } \\
\text { once } \\
\text { Vicarious racial } \\
\text { discrimination scale was } \\
\text { derived by taking the mean } \\
\text { of responses across these } \\
\text { four items. }\end{array}$ \\
\hline
\end{tabular}




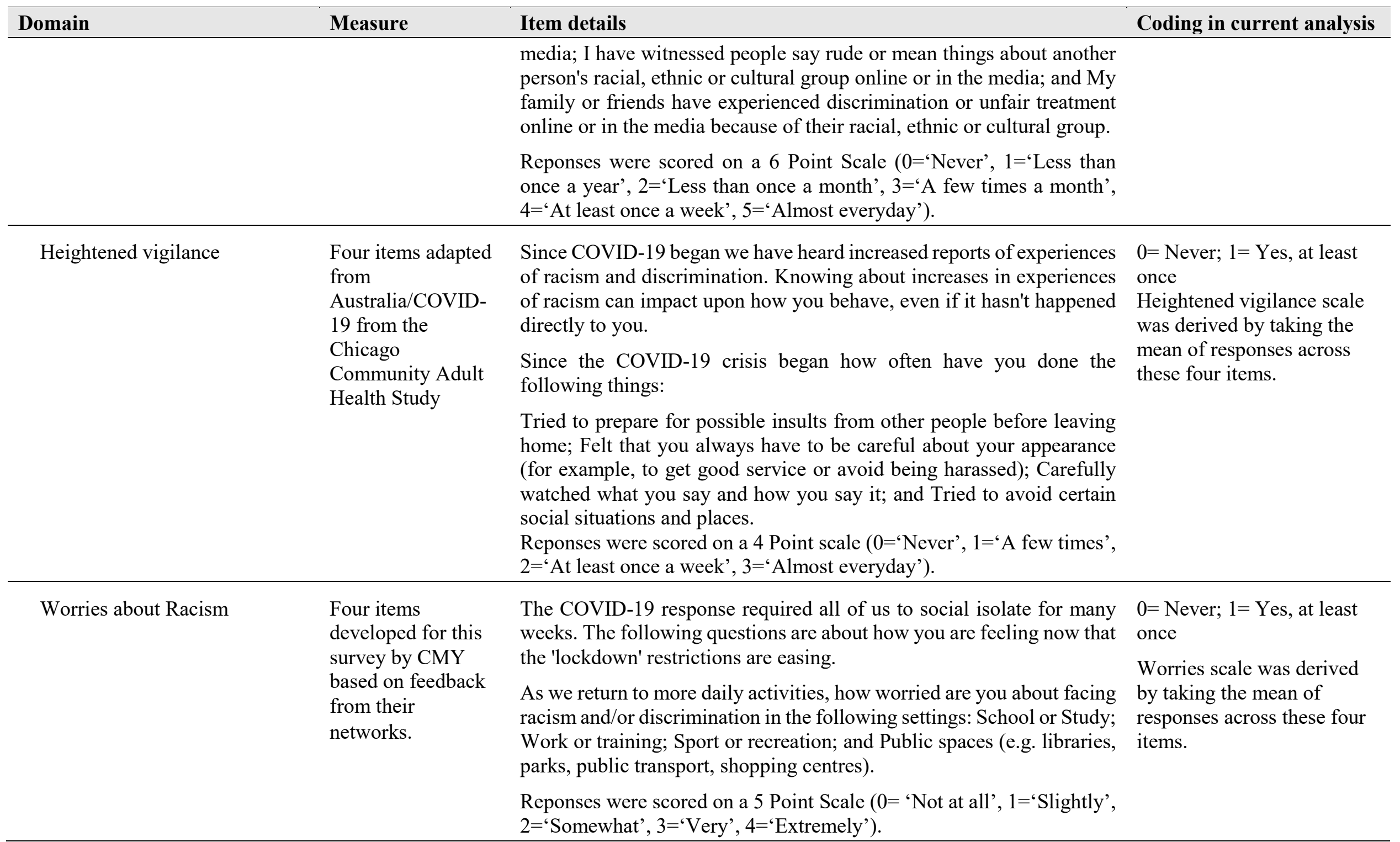




\begin{tabular}{|c|c|c|c|}
\hline Domain & Measure & Item details & Coding in current analysis \\
\hline \multirow[t]{4}{*}{ Responses to discrimination } & \multirow[t]{4}{*}{$\begin{array}{l}\text { One item adapted } \\
\text { form the Measure } \\
\text { of Indigenous } \\
\text { Racism } \\
\text { Experiences }\end{array}$} & $\begin{array}{l}\text { The following questions are about how you responded to racism or } \\
\text { unfair treatment, and the response and support you received. We } \\
\text { recognise that you may have had more than one experience, and so may } \\
\text { have reported some experiences and not others - please answer all } \\
\text { questions relevant to your experiences. }\end{array}$ & \multirow[t]{4}{*}{$\begin{array}{l}0=\text { No, didn't receive } \\
\text { support; } 1=\text { Yes, received } \\
\text { support }\end{array}$} \\
\hline & & $\begin{array}{l}\text { When you experienced discrimination or unfair treatment because of } \\
\text { your ethnicity, cultural background, religion or immigrant status what } \\
\text { did you do? (you can select multiple options) }\end{array}$ & \\
\hline & & $\begin{array}{l}\text { Response options were: 'Ignored it'; 'Got angry'; 'Fought back'; } \\
\text { 'Talked about it with friends or family'; 'Talked about it with a teacher, } \\
\text { health professional or other workers'; 'Laughed about it'; 'Reported it'; } \\
\text { and 'Other'. }\end{array}$ & \\
\hline & & $\begin{array}{l}\text { Participants were also asked 'Following your experience of racism or } \\
\text { unfair treatment, did you receive any support or help to cope?' The } \\
\text { response options were: 'Yes, when I reported it I was offered support } \\
\text { from a professional/service'; 'Yes, I reached out for support from a } \\
\text { professional/service'; 'Yes, my friends/family offered me support'; } \\
\text { 'No when I reported it I was not offered/referred to any support'; 'No, } \\
\text { I did not know where to get help or support'; 'No, I didn't think I } \\
\text { needed it'; and 'Other' }\end{array}$ & \\
\hline \multicolumn{4}{|l|}{ COVID-19 Stressors } \\
\hline \multirow[t]{2}{*}{ Stressors due to COVID-19 } & \multirow[t]{2}{*}{$\begin{array}{l}\text { Eleven items } \\
\text { adapted from the } \\
\text { CoRonavIruS } \\
\text { Health Impact } \\
\text { Survey (CRISIS) } \\
\text { survey. }\end{array}$} & $\begin{array}{l}\text { In the last two weeks... How often are you getting outside your house } \\
\text { for activities such as exercising, shopping for food, attending a medical } \\
\text { appointment, work or school where necessary? } \\
\text { Responses scored on a } 5 \text { point scale ( } 0=\text { Several times a day; } 1=\text { Once } \\
\text { a day, } 2=\text { Several times a week, } 3=\text { Once a week, } 4=\text { Never). }\end{array}$ & \multirow{2}{*}{$\begin{array}{l}\text { Binary variable with the } \\
\text { three more positive response } \\
\text { options }(0-2) \text { combined to } \\
\text { be recoded as ' } 0 \text { ', and the } \\
\text { two more negative response } \\
\text { options }(3 \& 4) \text { recoded to } \\
\text { be ' } 1 \text { '. }\end{array}$} \\
\hline & & $\begin{array}{l}\text { In the last two weeks... How stressful have the restrictions on leaving } \\
\text { home been for you? }\end{array}$ & \\
\hline
\end{tabular}


Responses scored on a 5 point scale $(0=$ Not at all, $1=$ Slightly, $2=$ Somewhat, $3=$ Very, 4= Extremely).

In the last two weeks... Has the quality of your relationships with your family changed?

Responses scored on a 5 point scale $(0=\mathrm{A}$ lot better, $1=\mathrm{A}$ little better, $2=$ About the same, $3=$ A little worse, $4=$ A lot worse).

In the last two weeks... Has the quality of your relationships with your friends changed?

Responses scored on a 5 point scale $(0=\mathrm{A}$ lot better, $1=\mathrm{A}$ little better, $2=$ About the same, $3=$ A little worse, $4=$ A lot worse).

In the last two weeks... How much have changes related to the COVID19 created financial problems for you or your family?

Responses scored on a 5 point scale $(0=$ Not at all, $1=$ Slightly, $2=$ Somewhat, 3= Very, 4= Extremely).

In the last two weeks... How difficult has it been to access the supports and services (e.g. Centrelink/income support or health services) to meet your and/or your family's needs?

Responses scored on a 5 point scale $(0=$ Not at all, $1=$ Slightly, $2=$ Somewhat, 3= Very, 4= Extremely)

In the last two weeks... Did you worry whether your food would run out because of a lack of money?

Responses scored on a 5 point scale $(0=$ Not at all, $1=$ Slightly, $2=$ Somewhat, $3=$ Very, 4= Extremely).

How has your life changed as a result of COVID-19? How much are you helping family, friends and community members understand information about COVID-19?
0 Stressors; $1-2$ stressors; $3+$ Stressors

$0-2$ Stressors; $3+$ Stressors 


\begin{tabular}{|c|c|c|c|}
\hline Domain & Measure & Item details & Coding in current analysis \\
\hline & & $\begin{array}{l}\text { Responses scored on a } 5 \text { point scale }(0=\text { Never, } 1=\text { Rarely, } 2= \\
\text { Occasionally, } 3=\text { Often, } 4=\text { Most of the time }) \text {. }\end{array}$ & \\
\hline & & $\begin{array}{l}\text { How has your life changed as a result of COVID-19? How much are } \\
\text { you having to care for family members, e.g. children, elderly relatives, } \\
\text { compared to before COVID-19? }\end{array}$ & \\
\hline & & $\begin{array}{l}\text { Responses scored on a } 5 \text { point scale }(0=\text { A lot less, } 1=\text { A little less, } 2= \\
\text { About the same, } 3=\text { A little more, } 4=\text { A lot more }) \text {. }\end{array}$ & \\
\hline & & $\begin{array}{l}\text { Since the COVID-19 Crisis began... How worried have you been } \\
\text { about you or your family and friends being infected with COVID-19? }\end{array}$ & \\
\hline & & $\begin{array}{l}\text { Responses scored on a } 5 \text { point scale }(0=\text { Not at all, } 1=\text { Slightly, } 2= \\
\text { Somewhat, } 3=\text { Very, } 4=\text { Extremely }) \text {. }\end{array}$ & \\
\hline & & $\begin{array}{l}\text { Since the COVID-19 Crisis began... Have your worries for the } \\
\text { wellbeing of friends or family overseas increased since COVID-19? }\end{array}$ & \\
\hline & & $\begin{array}{l}\text { Responses scored on a } 5 \text { point scale }(0=\text { Not at all, } 1=\text { Slightly, } 2= \\
\text { Somewhat, } 3=\text { Very, } 4=\text { Extremely }) \text {. }\end{array}$ & \\
\hline \multicolumn{4}{|c|}{ Mental and emotional wellbeing } \\
\hline \multirow[t]{4}{*}{ Mental Health Symptoms } & $\begin{array}{l}\text { Eight items from } \\
\text { adapted from the } \\
\text { CRSIS Survey. }\end{array}$ & $\begin{array}{l}\text { COVID-19 has led to a lot of change in everyday life for young people. } \\
\text { The following questions are about how COVID-19 has affected you. } \\
\text { IN THE LAST TWO WEEKS... }\end{array}$ & \multirow{4}{*}{$\begin{array}{l}\text { Responses were recoded } \\
\text { to create two binary } \\
\text { variable 'Moderate/ Low/ } \\
\text { Very Low' }=0 \text {, 'High/ } \\
\text { Very High' }=1 \text {; and 'Low/ } \\
\text { Very Low' }=0 \text {, 'Moderate- } \\
\text { Very High' }=1 \text {. }\end{array}$} \\
\hline & & ... how worried were you generally? & \\
\hline & & $\begin{array}{l}\text { Response were scored on a } 5 \text { point scale }(0=\text { Not at all worried, } 1= \\
\text { Slightly Worried, } 2=\text { A bit worried, } 3=\text { Very worried, } 4=\text { Extremely } \\
\text { worried }) \text {. }\end{array}$ & \\
\hline & & ... how happy or sad were you? & \\
\hline
\end{tabular}


Response were scored on a 5 point scale $(0=$ Very happy/ cheerful, $1=$ A bit happy/ cheerful, $2=$ Neutral, $3=\mathrm{A}$ bit sad/ depressed/ unhappy, $4=$ Very sad/ depressed/ unhappy).

...how relaxed or anxious were you?

Response were scored on a 5 point scale $(0=$ Very relaxed $/ \mathrm{calm}, 1=\mathrm{A}$ bit relaxed/ calm, $2=$ Neutral, $3=\mathrm{A}$ bit nervous/ anxious, $4=$ Very nervous/ Anxious).

... how fidgety or restless were you?

Response were scored on a 5 point scale $(0=$ Not fidgety/ restless at all, $1=$ Slight fidgety $/$ restless, $2=$ Neutral, $3=\mathrm{A}$ bit fidgety $/$ restless, and $4=$ Very fidgety/ restless).

...how fatigued or tired were you?

Response were scored on a 5 point scale $(0=$ Not fatigued or tired at all, $1=$ Slightly fatigued or tired, $2=$ Moderately fatigued or tired, $3=$ Very fatigued or tired, $4=$ Very fatigued or tired).

... how well were you able to concentrate or focus?

Responses were scored on a 5 point scale $(0=$ Very focused/ attentive, $1=\mathrm{a}$ bit focused/attentive, $2=$ Neutral, $3=\mathrm{A}$ bit unfocused. Distracted, $4=$ very unfocused/ distracted).

... how irritable or easily angered were you.?

Responses were scored on a 5 point scale $(0=$ Not at all irritable/ easily angered, $1=$ Slightly irritable/ easily angered, $2=\mathrm{A}$ bit irritable/ easily angered, $3=$ Very irritable/ easily angered, $4=$ Extremely irritable/ easily angered).
These binary variables were combined to create two summary count variables of the total number of High/ Very High mental health symptoms (1+ symptom) and $(2+$ symptoms $)$ as well as Moderate- Very High mental health symptoms (1+ symptom) and (2+ Symptoms).

A mental health scale was derived by adding the total score across all eight items.

... how lonely were you? 
Response were scored on a 5 point scale $(0=$ Not at all lonely, $1=$ Slightly lonely, 2=A bit lonely, $3=$ Very lonely, 4= Extremely lonely).

Support for Emotional

Wellbeing
'COVID-19 has led to a lot of change in everyday life for young people. The following questions are about how COVID-19 has affected you. 'Since the COVID-19 crisis began: ... Have you reached out for support for your emotional wellbeing?'

Response options were 'Yes, from family and friends'; 'Yes, from a professional/ service'; 'No, I didn't know where to go/ who to ask'; 'No, I didn't feel comfortable asking for support'; 'No, it was too difficult because of social distancing and staying at home'; and 'No, I didn't think I needed it.'
$0=$ No, didn't receive support; $1=$ Yes, received support. 
Supplementary File Table B- Missing data overall and by key covariates

\begin{tabular}{|c|c|c|c|c|c|c|c|c|}
\hline & Total n(\%) & $\begin{array}{l}\text { Anglo/Europ } \\
\text { ean } n(\%)\end{array}$ & $\begin{array}{c}\text { Multicultural } \\
\mathbf{n}(\%)\end{array}$ & $\begin{array}{l}\text { Aboriginal } \\
\text { and/or } \\
\text { Torres Strait } \\
\text { Islander } \\
\text { n(\%) } \\
\end{array}$ & Male n(\%) & Female n(\%) & $\begin{array}{c}\text { Under } 18 \\
\text { n(\%) }\end{array}$ & $\begin{array}{c}\text { Over } 18 \\
\text { n(\%) }\end{array}$ \\
\hline Direct discrimination & $112(30.85)$ & $50(28.57)$ & $49(30.82)$ & $5(38.46)$ & $41(35.04)$ & $67(28.15)$ & $0(0.00)$ & $0(0.00)$ \\
\hline Vicarious racism & $103(28.37)$ & $45(25.71)$ & $45(28.30)$ & $5(38.46)$ & $37(31.62)$ & $62(26.05)$ & $0(0.00)$ & $1(1.11)$ \\
\hline Heightened vigilance & $109(30.03)$ & $48(27.43)$ & $48(30.19)$ & $5(38.46)$ & $39(33.33)$ & $66(27.73)$ & $0(0.00)$ & $0(0.00)$ \\
\hline Worry & $116(31.96)$ & $55(31.43)$ & $47(29.56)$ & $5(38.46)$ & $41(35.04)$ & $71(29.83)$ & $7(5.69)$ & $5(5.56)$ \\
\hline Stressors & $59(16.25)$ & $23(13.14)$ & $28(17.61)$ & $3(23.08)$ & $21(17.95)$ & $35(14.71)$ & $0(0.00)$ & $0(0.00)$ \\
\hline $\begin{array}{l}\text { Mental Health } \\
\text { Symptoms }\end{array}$ & $93(25.62)$ & $38(21.71)$ & $43(27.04)$ & $5(38.46)$ & 35 (29.91) & $54(22.69)$ & $0(0.00)$ & $0(0.00)$ \\
\hline
\end{tabular}


Supplementary File Table C: Key study variables overall and by ethnicity

\begin{tabular}{|c|c|c|c|c|}
\hline & Anglo/Euro & $\begin{array}{l}\text { Multicultural } \\
\text { Backgrounds }\end{array}$ & $\begin{array}{c}\text { Aboriginal } \\
\text { and/or Torres } \\
\text { Strait Islander }\end{array}$ & Total \\
\hline & $\begin{array}{c}M(\mathrm{SD}) \text { or } \mathrm{N} \\
95 \% \mathrm{CI})\end{array}$ & $\begin{array}{c}M(\mathrm{SD}) \text { or } \mathrm{N} \\
95 \% \mathrm{CI})\end{array}$ & $\begin{array}{c}M(\mathrm{SD}) \text { or } \mathrm{N} \\
95 \% \mathrm{CI})\end{array}$ & $\begin{array}{c}M(\mathrm{SD}) \text { or } \mathrm{N} \\
95 \% \mathrm{CI})\end{array}$ \\
\hline Socio-demographics & $(n=175)$ & $(n=159)$ & $(n=13)$ & $(n=363)$ \\
\hline \multicolumn{5}{|l|}{ Gender } \\
\hline Male & $58(33.14)$ & $50(31.45)$ & $<5$ & $117(32.23)$ \\
\hline Female & $112(64.00)$ & $107(67.30)$ & $10(76.92)$ & $238(65.56)$ \\
\hline Missing & $1(0.57)$ & $0(0.00)$ & $0(0.00)$ & $1(0.28)$ \\
\hline \multicolumn{5}{|l|}{ Age } \\
\hline Under 18 & $54(30.86)$ & $33(20.75)$ & $2(15.38)$ & $90(24.79)$ \\
\hline Over 18 & $59(33.71)$ & $54(33.96)$ & $5(38.46)$ & $123(38.68)$ \\
\hline Missing & $62(35.43)$ & $72(45.28)$ & $6(46.15)$ & $150(41.32)$ \\
\hline \multicolumn{5}{|l|}{ Country of birth } \\
\hline Australia & $169(96.57)$ & $38(23.90)$ & $12(92.31)$ & $231(63.64)$ \\
\hline Overseas & $6(3.43)$ & $121(75.10)$ & $0(0.00)$ & $131(36.09)$ \\
\hline Missing & $0(0.00)$ & $0(0.00)$ & $1(7.69)$ & $1(0.28)$ \\
\hline \multicolumn{5}{|l|}{$\begin{array}{l}\text { Generation in } \\
\text { Australia }\end{array}$} \\
\hline 1st Generation ${ }^{1}$ & $6(3.43)$ & $121(76.10)$ & $0(0.00)$ & $131(36.09)$ \\
\hline 2nd Generation ${ }^{2}$ & $22(12.57)$ & $36(22.64)$ & $<5$ & $61(16.80)$ \\
\hline$\geq 3$ rd Generation ${ }^{3}$ & $145(82.86)$ & $<5$ & $11(84.62)$ & $166(45.73)$ \\
\hline Missing & $2(1.11)$ & $1(0.62)$ & $1(7.69)$ & $5(1.38)$ \\
\hline \multicolumn{5}{|l|}{$\begin{array}{l}\text { Length of time in } \\
\text { Australia (If born } \\
\text { Overseas) }(n=131)\end{array}$} \\
\hline$<5$ Years & $<5$ & $52(42.98)$ & $0(0.00)$ & $56(42.75)$ \\
\hline 5-10 years & $<5$ & $32(26.45)$ & $0(0.00)$ & $35(26.72)$ \\
\hline$\geq 10$ years & $<5$ & $34(28.10)$ & $0(0.00)$ & $37(28.24)$ \\
\hline Missing & $0(0.00)$ & $3(1.89)$ & $0(0.00)$ & $3(2.29)$ \\
\hline \multicolumn{5}{|l|}{$\begin{array}{l}\text { Language Spoken at } \\
\text { home }\end{array}$} \\
\hline English only & $160(91.43)$ & $17(10.69)$ & $11(84.62)$ & $200(55.10)$ \\
\hline $\begin{array}{l}\text { English and a } \\
\text { second language }\end{array}$ & $12(6.86)$ & $99(62.26)$ & $<5$ & $115(31.68)$ \\
\hline
\end{tabular}




\begin{tabular}{|c|c|c|c|c|}
\hline $\begin{array}{l}\text { Language other than } \\
\text { English }\end{array}$ & $<5$ & $43(27.04)$ & $0(0.00)$ & $47(12.95)$ \\
\hline Missing & $1(0.57)$ & $0(0.00)$ & $0(0.00)$ & $1(0.28)$ \\
\hline \multicolumn{5}{|l|}{ SEIF4 $4^{1}$} \\
\hline Top 75 Percentile & $69(39.43)$ & $56(35.22)$ & $<5$ & $133(36.64)$ \\
\hline $\begin{array}{l}\text { Bottom } 25 \\
\text { Percentile }\end{array}$ & $44(25.14)$ & $34(21.38)$ & $<5$ & $84(23.14)$ \\
\hline Missing & $62(35.43)$ & $69(43.40)$ & $5(38.46)$ & $146(40.22)$ \\
\hline \multicolumn{5}{|l|}{ Rurality } \\
\hline Major City & $44(22.86)$ & $25(32.70)$ & $<5$ & $98(27.00)$ \\
\hline Regional Victoria & $73(41.71)$ & $38(23.90)$ & $6(46.15)$ & $119(32.78)$ \\
\hline Missing & $62(35.43)$ & $69(43.40)$ & $5(38.46)$ & $146(40.22)$ \\
\hline $\begin{array}{l}\text { Mental health } \\
\text { symptoms }\end{array}$ & $(n=137)$ & $(\mathrm{n}=116)$ & $(n=8)$ & $(n=270)$ \\
\hline $\begin{array}{l}1+\text { symptoms high } \\
\text { distress }\end{array}$ & $136(99.27)$ & 109 (93.97) & $8(100.00)$ & $262(97.04)$ \\
\hline $\begin{array}{l}2+\text { symptoms high } \\
\text { distress }\end{array}$ & $128(93.43)$ & $104(89.66)$ & $8(100.00)$ & $248(91.85)$ \\
\hline $\begin{array}{l}\text { Mental Health } \\
\text { Symptoms (mean of } \\
\text { total score } 0-32 \text { ) }\end{array}$ & $\begin{array}{c}15.95(14.95 \\
16.94)\end{array}$ & $\begin{array}{c}14.67(13.57 \\
15.77)\end{array}$ & $\begin{array}{c}18.38(12.18 \\
24.57)\end{array}$ & $\begin{array}{c}15.43(14.71 \\
16.15)\end{array}$ \\
\hline $\begin{array}{l}\text { COVID-19 Related } \\
\text { Stressors }\end{array}$ & $(n=152)$ & $(\mathrm{n}=131)$ & $(\mathrm{n}=10)$ & $(n=304)$ \\
\hline 0 Stressors & $20(13.16)$ & $19(14.50)$ & $<5$ & $44(14.47)$ \\
\hline 1-2 stressors & $93(61.18)$ & $55(41.98)$ & $<5$ & $156(51.32)$ \\
\hline $3+$ stressors & $39(25.66)$ & $57(43.51)$ & $5(50.00)$ & $104(34.21)$ \\
\hline \multicolumn{5}{|l|}{ Discrimination } \\
\hline Direct discrimination & $(n=125)$ & $(n=110)$ & $(n=8)$ & $(n=251)$ \\
\hline Any direct & $81(64.80)$ & $94(85.45)$ & $6(75.00)$ & $185(73.71)$ \\
\hline Direct (mean) & $0.29(0.20,0.39)$ & $0.68(0.53,0.83)$ & $\begin{array}{c}0.88(-0.08 \\
1.83)\end{array}$ & $0.48(0.39,0.56)$ \\
\hline Vicarious racism & $(\mathrm{n}=130)$ & $(n=114)$ & $(n=8)$ & $(n=260)$ \\
\hline Any vicarious & $113(86.92)$ & $105(92.11)$ & $8(100.00)$ & $231(88.85)$ \\
\hline Vicarious (mean) & $1.49(1.30,1.68)$ & $2.70(2.44,2.97)$ & $3.56(2.88,4.25)$ & $2.01(1.90,2.25)$ \\
\hline Heightened vigilance & $(n=127)$ & $(\mathrm{n}=111)$ & $(n=8)$ & $(n=254)$ \\
\hline $\begin{array}{l}\text { Any Heightened } \\
\text { vigilance }\end{array}$ & 99 (77.95) & 103 (92.79) & $7(87.50)$ & $214(84.25)$ \\
\hline
\end{tabular}




\begin{tabular}{lcccc}
$\begin{array}{l}\text { Heightened } \\
\text { vigilance (mean) }\end{array}$ & $0.84(0.12,0.97)$ & $1.38(1.20,1.55)$ & $1.13(0.64,1.61)$ & $1.07(0.96,1.17)$ \\
$\begin{array}{l}\text { Worry about } \\
\text { experiencing racism }\end{array}$ & $(\mathrm{n}=120)$ & $(\mathrm{n}=112)$ & $(\mathrm{n}=8)$ & $(\mathrm{n}=247)$ \\
Any worries & $47(39.83)$ & $98(87.50)$ & $8(100.00)$ & $155(62.75)$ \\
Worries (mean) & $0.46(0.32,0.60)$ & $1.46(1.27,1.65)$ & $1.18(0.32,2.04)$ & $0.93(0.80,1.06)$ \\
\hline
\end{tabular}

Note: Results are presented as a proportion of the number of participants who answered at least one question from each scale or group of items. ${ }^{1}$ First Generation- Born in Australia; ${ }^{2}$ Second Generation- Born in Australia and parent/s born overseas; ${ }^{3}$ At least third Generation- Born in Australia and both parents born in Australia; ${ }^{4}$ Socio-Economic Indexes for Areas (SEIFA) 
Supplementary File Table D- Unadjusted and adjusted regression results for association between ethnicity and racial discrimination and stressor experiences during COVID-19 pandemic

\begin{tabular}{|c|c|c|c|c|c|c|c|c|c|c|}
\hline & \multicolumn{2}{|c|}{$\begin{array}{c}\text { Direct racial } \\
\text { discrimination }\end{array}$} & \multicolumn{2}{|c|}{ Vicarious Racism } & \multicolumn{2}{|c|}{ Heightened vigilance } & \multicolumn{2}{|c|}{ Worries } & \multicolumn{2}{|c|}{$\begin{array}{c}\text { COVID-19 related } \\
\text { Stressors }\end{array}$} \\
\hline & $\begin{array}{c}\text { Unadjusted } \\
\text { Coeff }(95 \% \\
\text { CI }) \\
(n=251)\end{array}$ & $\begin{array}{c}\text { Adjusted \# } \\
\text { Coeff }(95 \% \\
\text { CI }) \\
(n=213) \\
\end{array}$ & $\begin{array}{c}\text { Unadjusted } \\
\text { Coeff }(95 \% \\
\text { CI }) \\
(n=260)\end{array}$ & $\begin{array}{c}\text { Adjusted \# } \\
\text { Coeff }(95 \% \\
\text { CI }) \\
(n=213) \\
\end{array}$ & $\begin{array}{c}\text { Unadjusted } \\
\text { Coeff }(95 \% \\
\text { CI }) \\
(n=254)\end{array}$ & $\begin{array}{c}\text { Adjusted \# } \\
\text { IRR }(95 \% \\
\text { CI }) \\
(n=213) \\
\end{array}$ & $\begin{array}{c}\text { Unadjusted } \\
\text { IRR }(95 \% \\
\text { CI }) \\
(n=247) \\
\end{array}$ & $\begin{array}{c}\text { Adjusted \# } \\
\text { Coeff }(95 \% \\
\text { CI }) \\
(n=201) \\
\end{array}$ & $\begin{array}{c}\text { Unadjusted } \\
\text { IRR }(95 \% \\
\text { CI }) \\
(n=293) \\
\end{array}$ & $\begin{array}{c}\text { Adjusted \# } \\
\text { IRR (95\% } \\
\text { CI) } \\
(n=213) \\
\end{array}$ \\
\hline $\begin{array}{l}\text { Multicultural } \\
\text { backgrounds } \\
\text { (mean) }\end{array}$ & $\begin{array}{c}0.39(0.21 \\
0.56)\end{array}$ & $\begin{array}{c}0.22(0.06 \\
0.38)\end{array}$ & $\begin{array}{c}1.21(0.90 \\
1.53)\end{array}$ & $\begin{array}{c}1.05(0.69 \\
1.40)\end{array}$ & $\begin{array}{c}0.54(0.33 \\
0.74)\end{array}$ & $\begin{array}{c}0.46(0.23 \\
0.70)\end{array}$ & $\begin{array}{c}1.00(0.77 \\
1.24)\end{array}$ & $\begin{array}{c}0.82(0.56 \\
1.07)\end{array}$ & $\begin{array}{l}1.70(1.13 \\
2.51)\end{array}$ & $\begin{array}{c}1.62(1.02 \\
2.59)\end{array}$ \\
\hline $\begin{array}{l}\text { Aboriginal } \\
\text { and/or Torres } \\
\text { Strait Islander }\end{array}$ & $\begin{array}{c}0.58(0.09 \\
1.07)\end{array}$ & $\begin{array}{c}0.73(0.29 \\
1.17)\end{array}$ & $\begin{array}{c}2.07(1.18 \\
2.97)\end{array}$ & $\begin{array}{c}2.15(1.18 \\
3.11)\end{array}$ & $\begin{array}{c}0.29(-0.30 \\
0.87)\end{array}$ & $\begin{array}{c}0.27(-0.36 \\
0.90)\end{array}$ & $\begin{array}{c}0.72(0.07 \\
1.37)\end{array}$ & $\begin{array}{c}0.80(0.11 \\
1.49)\end{array}$ & $\begin{array}{c}1.94(0.77 \\
4.94)\end{array}$ & $\begin{array}{c}1.72(0.60 \\
4.90)\end{array}$ \\
\hline Anglo/European & 1 (ref) & 1 (ref) & 1 (ref) & 1 (ref) & 1 (ref) & 1 (ref) & 1 (ref) & 1 (ref) & 1 (ref) & 1 (ref) \\
\hline
\end{tabular}

\# Adjusted for Gender, Age \& SEIFA

\section{Supplementary File Table E: Unadjusted and adjusted associations between discrimination and stressors with mental health}

\begin{tabular}{lcc}
\hline & $\begin{array}{c}\text { Unadjusted } \\
\text { Coef }(95 \% \mathrm{CI})\end{array}$ & $\begin{array}{c}\text { Adjusted \# } \\
\text { Coef }(95 \% \mathrm{CI})\end{array}$ \\
\hline Direct $(\mathrm{n}=251 ; 205)$ & $1.17(0.10,2.25)$ & $2.58(1.07,4.07)$ \\
Vicarious $(\mathrm{n}=260 ; 205)$ & $0.86(0.34,1.37)$ & $1.50(0.83,2.16)$ \\
Heightened vigilance $(\mathrm{n}=254 ; 205)$ & $1.48(0.61,2.35)$ & $12.06(1.02,3.10)$ \\
Worry $(\mathrm{n}=247 ; 194)$ & $1.10(0.38,1.82)$ & $1.83(0.87,2.79)$ \\
Stressors $(\mathrm{n}=270 ; 205)$ & $3.90(2.47,5.33)$ & $4.09(2.30,5.88)$ \\
\hline
\end{tabular}

\# Adjusted for Ethnicity, Gender, Age \& SEIFA 


\section{Supplementary File Table F- Responses to experiences of discrimination and support received for experiences of discrimination or emotional wellbeing}

\begin{tabular}{|c|c|c|c|c|}
\hline & Anglo/Euro & $\begin{array}{l}\text { Multicultural } \\
\text { Backgrounds }\end{array}$ & $\begin{array}{l}\text { Aboriginal } \\
\text { and/or Torres } \\
\text { Strait Islander } \\
\end{array}$ & Total \\
\hline & $\begin{array}{c}\text { M (SD) or N } \\
(\%)\end{array}$ & $\mathrm{M}(\mathrm{SD})$ or $\mathrm{N}(\%)$ & $\mathrm{M}(\mathrm{SD})$ or $\mathrm{N}(\%)$ & $\mathrm{M}(\mathrm{SD})$ or $\mathrm{N}(\%)$ \\
\hline Reported Racism & 103 & 109 & 8 & 225 \\
\hline Ignored it & $51(49.51)$ & $75(68.81)$ & $<5$ & $132(58.67)$ \\
\hline Got Angry & $17(16.50)$ & $22(20.18)$ & $<5$ & $44(19.56)$ \\
\hline Fought Back & $9(8.74)$ & $16(14.68)$ & $<5$ & $27(12.00)$ \\
\hline $\begin{array}{l}\text { Talked about it with friends or } \\
\text { family }\end{array}$ & $16(15.53)$ & $43(39.45)$ & $<5$ & $64(28.44)$ \\
\hline $\begin{array}{l}\text { Talked about it with a teacher, } \\
\text { health professional or other } \\
\text { worker }\end{array}$ & $<5$ & $11(10.09)$ & $<5$ & $16(7.11)$ \\
\hline Laughed about it & $15(14.56)$ & $24(22.02)$ & $0(0.00)$ & $40(17.78)$ \\
\hline Reported it & $<5$ & $8(7.34)$ & $<5$ & $14(6.22)$ \\
\hline Other & $31(30.10)$ & $10(9.17)$ & $0(0.00)$ & $42(18.67)$ \\
\hline $\begin{array}{l}\text { Received support for Emotional } \\
\text { wellbeing }\end{array}$ & 132 & 114 & 8 & 263 \\
\hline Yes, from friends and family & 45 (34.09) & $47(41.23)$ & $6(75.00)$ & $101(38.40)$ \\
\hline Yes, from professional/service & $21(15.91)$ & $8(7.02)$ & $<5$ & $32(12.17)$ \\
\hline Yes, received support & $58(43.94)$ & $53(46.49)$ & $6(75.00)$ & $120(45.63)$ \\
\hline $\begin{array}{l}\text { No, I didn't know where to go / } \\
\text { who to ask }\end{array}$ & $<5$ & $8(7.02)$ & $0(0.00)$ & $12(4.56)$ \\
\hline $\begin{array}{l}\text { No, I didn't feel comfortable } \\
\text { asking for support }\end{array}$ & $22(16.67)$ & $15(13.16)$ & $<5$ & $40(15.21)$ \\
\hline $\begin{array}{l}\text { No, it was too difficult because of } \\
\text { social distancing and staying at } \\
\text { home }\end{array}$ & $<5$ & $8(7.02)$ & $0(0.00)$ & $10(3.80)$ \\
\hline No, I didn't think I needed it & $57(43.18)$ & $42(36.84)$ & $<5$ & $105(39.92)$ \\
\hline No, Didn't receive support & $74(56.06)$ & $61(53.51)$ & $<5$ & $143(54.37)$ \\
\hline
\end{tabular}

